\title{
Activated intestinal macrophages in patients with cirrhosis release NO and IL-6 that may disrupt intestinal barrier function
}

\author{
Johannie Du Plessis ${ }^{1}$, Hanne Vanheel ${ }^{8}$, Carl E.I. Janssen ${ }^{7}$, Leonie Roos ${ }^{1}$, Tomas Slavik ${ }^{2}$, \\ Paraskevi I. Stivaktas ${ }^{3}$, Martin Nieuwoudt ${ }^{1}$, Stefan G. van Wyk $^{1}$, Warren Vieira ${ }^{4}$, Etheresia Pretorius ${ }^{5}$, \\ Mervyn Beukes ${ }^{6}$, Ricard Farré ${ }^{8}$, Jan Tack ${ }^{8}$, Wim Laleman ${ }^{9}$, Johan Fevery ${ }^{9}$, Frederik Nevens ${ }^{9}$, Tania \\ Roskams ${ }^{10}$, Schalk W. Van der Merwe $\mathrm{e}^{1,9, *}$ \\ ${ }^{1}$ Hepatology and GI Research Laboratory, Department of Immunology, University of Pretoria, South Africa; \\ ${ }_{3}^{2}$ Department of Pathology, University of Pretoria, South Africa; \\ ${ }^{3} M R C$ Unit of Inflammation and mmunity, Department of mmunology, University of Pretoria and Tshwane Academic Division of the National \\ Health Laboratory Service, South Africa; \\ ${ }^{4}$ Department of Anatomy, Electron Microscopy Unit, University of Pretoria, South Africa; \\ ${ }^{5}$ Department of Physiology, University of Pretoria, South Africa; ${ }^{\circ}$ Department of Biochemistry, University of Pretoria, South Africa; \\ ${ }^{7}$ Translational Cell and Tissue Research, KU Leuven, Leuven, Belgium; \\ ${ }^{8}$ Translational Research Center for Gastrointestinal Disorders, KU Leuven, Leuven, Belgium; \\ ${ }^{9}$ Department of Hepatology, University of Leuven, Belgium; \\ ${ }^{10}$ Department of Morphology and Molecular Pathology, University of Leuven, Belgium
}

Background \& Aims: Bacterial infections commonly occur in decompensated cirrhosis resulting from bacterial translocation from the intestine. We studied the role of intestinal macrophages and the epithelial barrier in cirrhosis.

Methods: Forty-four patients with NASH/ASH cirrhosis (decom-pensated $n=29$, compensated $n=15$ ) and nineteen controls undergoing endoscopy were recruited. Serum was obtained and LPS and LBP levels determined. Intestinal macrophages were characterized by flow cytometry, immunohistochemistry, and nitric oxide (NO) production measured in supernatant of cultured duodenal samples. Quantitative RT-PCR was performed on duo-denal biopsies assessing 84 inflammatory genes. Protein levels of cytokines/chemokines were assessed in serum and superna-tant. The duodenal wall was assessed by electron microscopy, tight junction protein expression determined by RT-PCR, immu-nohistochemistry, and Western blot and, functional analysis performed by transepithelial resistance measurement and per-meability studies.

Results: Increased plasma LPS, LBP levels and higher numbers of duodenal CD $33^{+} / \mathrm{CD} 14^{+} /$Trem $-1^{+}$macrophages, synthesizing iNOS and secreting NO were present in decompensated cirrhosis. Upregulation of IL-8, CCL2, CCL13 at the transcriptional level, and increased IL-8, and IL-6 were detected in supernatant and serum in cirrhosis. IL-6 and IL-8 co-localised with iNOS ${ }^{+}$and CD68 ${ }^{+}$, but not with $\mathrm{CD} 11 \mathrm{c}^{+}$cells. Electron microscopy demon-strated an intact epithelial barrier. Increased Claudin-2 was detected by Western blot and immunohistochemistry, while decreased transepithelial resistance and increased duodenal per-meability were detected in decompensated cirrhosis. Conclusions: Our study shows the presence of activated CD $14^{+-}$Trem $^{-{ }^{+}}{ }^{\text {iNOS }}{ }^{+}$intestinal macrophages, releasing IL-6, NO, and increased intestinal permeability in patients with cirrhosis, sug-gesting that these cells may produce factors capable of enhancing permeability to bacterial products.

Keywords: Bacterial translocation; Intestinal macrophages; Epithelial barrier; IL-6; Nitric oxide; Cirrhosis.

Content contained in the manuscript has in part been presented at the American Association for the Study of Liver Diseases (AASLD) meeting, Boston, 2010 and as an oral presentation at the European Association for the Study of the Liver (EASL), Barcelona, 2012

* Corresponding author. Address: UZ Leuven, campus Gasthuisberg, Herestraat 49, B - 3000 Leuven, Belgium.

E-mail address: Schalk.vandermerwe@uzleuven.be (S.W. Van der Merwe).

Abbreviations: LPS, lipopolysaccharide; NO, nitric oxide; LBP, lipopolysaccharidebinding protein; IHC, immunohistochemical staining; CD14, cluster of differentiation 14; TREM-1, triggering receptor expressed on myeloid cells- 1 ; iNOS/NOS2, inducible nitric oxide synthase 2; IL-8, interleukin 8; CCL2/MCP-1, chemokine (C-C motif) ligand 2; CCL13, chemokine (C-C motif) ligand 13; IL-6, interleukin 6; IBD, inflammatory bowel disease; NEC, necrotising enterocolitis; TNF- $\alpha$, tumor necrosis factor alpha; TEER, transepithelial resistance; TJ, tight junction.

\section{Introduction}

Bacterial infections occur commonly in decompensated cirrhosis, are associated with translocation from the intestine and impact early and late mortality [1]. The natural history of cirrhosis is also altered by circulating bacterial DNA, which even in the absence of culture positive infections, increases the risk of variceal bleeding, hepatic decompensation, and hepatorenal syndrome $[2,3]$.

The reason why the gut epithelial barrier fails in cirrhosis, facilitating translocation of bacterial products and DNA, remains poorly understood. In health, it provides an effective barrier to micro-organisms, but is simultaneously semi-permeable, allowing nutrient absorption [4]. It consists of enterocytes interconnected by tight and gap junctions. Tight junctions (TJ), 
composed of various proteins, are essential elements maintaining structural integrity and regulating permeability [5]. The expression and turnover of $\mathrm{TJ}$ proteins are influenced by inflammation and oxidative stress [6,7].

Intestinal macrophages localised within the lamina propria provide the first line of defence to micro-organisms breaching the epithelial barrier. In health, these cells are characterized by a specific phenotype, $\mathrm{CD} 33^{+} \mathrm{CD} 14^{-}$, are highly anergic and do not produce pro-inflammatory cytokines in response to lipopolysaccaride (LPS) [8,9]. In IBD, however, intestinal macrophages express innate response receptors such as CD14 ${ }^{+}$, TREM-1, and release pro-inflammatory cytokines [10]. Activated CD14 ${ }^{+}$macrophages in necrotising enterocolitis produce nitric oxide (NO) that impairs endothelial repair $[11,12]$. We have shown that macrophages activation in HIV correlated with bacterial translocation and persistent immune activation [13].

We hypothesized that similar to other inflammatory states, intestinal macrophage activation occurs in cirrhosis. The aims of our study were consequently to determine the intestinal macrophage phenotype in decompensated cirrhosis and whether these macrophages are capable of modulating permeability.

\section{Patients and methods}

\section{Study population}

Patients referred to the Interventional endoscopy unit, Pretoria East, between January 2008 and February 2011, were considered for this study. Cirrhosis was diagnosed by standard clinical, ultrasonographical, and/or histological criteria. Patients with confirmed NASH or alcoholic cirrhosis were included. Decompensated cirrhosis was defined as new onset ascites with or without variceal bleeding, encephalopathy or jaundice. Compensated cirrhosis was defined as patients without ascites, encephalopathy, history of variceal bleeding or a previous episode of decompensation. The protocol was approved by the University of Pretoria Ethics committee. Written informed consent was obtained from each patient or their legal representative.

Inclusion criteria were age 18-80 years and confirmed NASH or alcoholic cirrhosis. Exclusion criteria were: severe sepsis or SIRS with circulatory dysfunction, hepatocellular carcinoma, portal vein thrombosis, cardiac, renal or respiratory failure, previous luminal gastrointestinal surgery, antibiotic therapy or alcohol use in the preceding 6 weeks. Patients included underwent oesophagogastroduodenoscopy for variceal screening and duodenal biopsies were taken. Patients in the control group underwent endoscopy due to reflux/dyspepsia symptoms. The study population consisted of decompensated $(\mathrm{N}=29)$, compensated $(\mathrm{N}=15) \mathrm{NASH} / \mathrm{ASH}$ cirrhosis, and controls $(\mathrm{N}=19)$. In addition, 9 patients with ASH/NASH cirrhosis undergoing endoscopy for varices screening were recruited from the liver clinic University hospital, Gasthuisberg, Leuven, (Ethics protocols ML6697, ML8081), for TEER and permeability experiments, and the results compared to a control group.

\section{Biochemistry}

Blood samples were collected from a peripheral vein into sterile or endotoxin free tubes, centrifuged, and plasma stored at $-80^{\circ} \mathrm{C}$ until analysis. Analysis included standard full blood count, liver function tests, INR, CRP.

Plasma LPS and LBP levels

Circulating endotoxin (LPS) and lipopolysaccharide-binding protein (LBP) levels were analysed in duplicate in 96-well plates according to the manufacturer's instructions, Limulus Amoebocyte Lysate (LAL) assay QCL-1000 (Lonza, Valais Switzerland); LBP (Human) Elisa kit (Abnova, Taipei, Taiwan). The lower limit of detection for each assay is $\mathrm{LPS}=0.1 \mathrm{EU} / \mathrm{ml}$ and LBP $=5 \mathrm{ng} / \mathrm{ml}$ (Appendix A).
Tissue samples

Biopsies were obtained from the third part of the duodenum at endoscopy. Biopsies for flow cytometry were placed in cold RPMI 1640. Histological specimens were fixed in $10 \%$ formalin for light microscopy and $2.5 \%$ glutaraldehyde-formaldehyde for transmission electron microscopy (TEM). Biopsies for gene expression and Western blot were snap frozen and stored at $-80^{\circ} \mathrm{C}$. Biopsies for short-term culture studies were placed in cold, sterile PBS, and for TEER and permeability experiments in cold Hank's buffer.

Isolation of mucosal mononuclear cells (MMCs)

A single-cell suspension was obtained by means of GentleMACS dissociator (MiltenyiBiotec, Gladbach, Germany) according to the manufacturer's protocol (Appendix B).

Determination of macrophage phenotype

The phenotype of intestinal macrophages was determined assessing a panel of surface markers, characteristic of monocyte/macrophage lineage (CD33), activation status (CD14, CD16, Trem-1), and co-stimulatory molecules (CD80, CD86). In addition, we assessed the surface expression of the toll-like receptor 2 and 4 (TLR-2, and 4). Single-cell preparations in PEB buffer were stained with $20 \mu \mathrm{l}$ monoclonal antibodies $/ 100 \mu$ o f $10^{6}$ cells in two-colour combinations (Appendix C).

Gene expression

Following total RNA extraction (RNeasy and RNase-Free DNase kits, Qiagen, Hilden, Germany), RNA quantity and quality were confirmed by Nanodrop ND1000 (Thermo Scientific, DE, USA) and Experion ${ }^{\mathrm{TM}}$ (Bio-Rad) analysis, respectively. cDNA was synthesized from $2.0 \mu \mathrm{g}$ of total RNA using the RT ${ }^{2}$ PCR array first strand kit (SABioscience, Frederick, MD). The expression levels of 84 general inflammatory genes (Appendix D) were assessed by semi-quantitative RT-PCR in 96-well plates using RT ${ }^{2}$ SYBR Green qPCR Master Mix and a CFX96 RT-PCR Detection System (Bio-Rad, Hercules, CA). Fifteen decompensated cirrhotics and five controls were analysed. Data was normalized using five different housekeep-ing genes and analysed by the comparative cycle threshold method (REST 2009 V2.0.13 software Qiagen, Hilden, Germany).

Quantitative RT-PCR was then performed of 27 upregulated genes and alternative inflammatory pathways not included in the screening assay, in combination with the two most stable housekeeping genes as determined by geNorm software. (Appendix E). Fourteen decompensated cirrhotics, seven compensated cirrhotics and six controls were analysed in triplicate.

Duodenal biopsy cultures

Biopsy specimens were placed in PBS, washed, weighed and incubated in RPMI 1640 containing 10\% fetal calf serum (Sigma), $10 \mu \mathrm{l} / \mathrm{ml}$ Pen/Strep Amphotericin B (Cambrex, Walkersville, MD) and $1 \mu \mathrm{l} / \mathrm{ml}$ gentamicin (Genta50, Phenix Pharmaceutials, Belgium) at $37{ }^{\circ} \mathrm{C}$, in humidified $5 \% \mathrm{CO}_{2}$ for $48 \mathrm{~h}$. Supernatants were stored at $-70^{\circ} \mathrm{C}$ until further analysis.

Nitric oxide determination in culture supernatant

Biopsy samples were incubated with and without LPS $(1 \mu \mathrm{g} / \mathrm{ml}$, Sigma). Total nitrite and nitrate in supernatant were determined by Total Nitric Oxide and Nitrite/Nitrate Assay (R\&D Systems, Minneapolis, USA).

Cytokine determination

Cytokine and chemokine levels in plasma and biopsy culture supernatants, were quantified using a customized Bio-Plex Pro ${ }^{\mathrm{TM}}$ assay assessing IL-8, CCL2, IL-10, IL-6, TNF $\alpha$, according to manufacturer's protocol (Bio-Rad, Hercules, CA).

Histopathological and ultrastructural analysis of the duodenal wall

Histological analysis was conducted by a pathologist blinded to patient subgroups. Immunohistochemical staining for iNOS, CD14, CD68, CD11c, IL-6, IL-8, and Claudin-2 was performed. Double staining experiments with dye swap were 
performed to assess co-localisation of CD14 and CD68 with iNOS, CD68, and iNOS with IL-6 and IL-8, respectively, and CD11c with IL-6. TEM performed on glutaraldehyde-fixed specimens was analysed on a JOEL JEM 2100F microscope (Appen$\operatorname{dix}$ F)

Western blot

Western blot analysis was performed from membrane extracts of duodenal biopsy specimens. Biopsies were individually weighed and lysed in sample buffer (Appendix G). Samples were sonicated (Sonifier cell disruptor B-30, Dambury, CT USA) and protein concentrations determined (Bio-Rad, Hercules, CA, USA). Proteins $(75 \mu \mathrm{g})$ were separated by SDS-PAGE using Hoefer SE300 blotting system (Amersham, United Kingdom) and transferred to PVDF membranes (Bio-Rad, Hercules, CA, USA). Membranes were blotted for Claudin-1, Claudin-2, Connexin-43, Occludin, and Zona-Occludin 1 (Invitrogen, Camarillo, CA, USA) and GAPDH (Serotec, Kidlington, Oxford, United Kingdom) using polyclonal antibodies in combination with alkaline phosphatase conjugated secondary antibody. Blots were developed using Bio-Rad AP detection kit and densitometric comparisons performed using Quantity One1D analysis software (Bio-Rad, Hercules, CA, USA).

Ussing chamber experiments

Transepithelial electrical resistance (TEER) and passage of FITC-dx4 using 4 duodenal biopsies were measured in modified $3 \mathrm{ml}$ Ussing chambers (Mussler Scientific Instruments, Aachen, Germany). Biopsies were mounted as described previously [14]. ( Appendix H).

Statistical analysis

Data was entered into a Microsoft Excel 2007 spreadsheet. Using Statistix 9 (Analytical software, Tallahassee, FL, USA), non-parametric comparisons between observations in different groups were conducted with the Wilcoxon Rank Sum test. Paired observations within groups were compared using the Wilcoxon Signed Rank test. Two proportion Fisher exact tests were used for binary variables. Two-tailed $p$-values $<0.05$ were considered significant and linear correlations were assessed using Spearman's rank correlation coefficient. Between-group differences in TEER and FITC-dx4 passage were corrected for confounding factors using general linear models.

\section{Results}

Patient demographics, Child-Pugh status and biochemical parameters

The patient characteristics are summarized in Table 1 and reflect the degree of liver dysfunction and portal hypertension with decompensated cirrhotics having higher Child-Pugh and MELD scores compared to compensated cirrhotics. There were no differences between compensated and decompensated cirrhotics regarding the use of PPI or beta blocker medication.

Increased plasma LPS levels in decompensated but not compensated cirrhosis

We assessed LPS and LBP levels as surrogate markers of bacterial translocation. Both LPS and LPB levels were significantly increased in patients with cirrhosis (Fig. 1A and B). A weak but significant correlation was observed between Child-Pugh scores and LPS levels $(r=0.292, p=0.03)$.

Intestinal macrophages in the duodenum of patients with cirrhosis have an activated phenotype

Activated intestinal macrophages and dendritic cells play an important role in intestinal inflammation [10,12]. Immunohistochemistry confirmed a significant increase in $\mathrm{CD}^{+} 8^{+}$macrophages
(Fig. 1C and D). An increased frequency of intestinal macrophages expressing CD33/CD14 and co-expressing receptors for CD33/ CD14/Trem-1 by FACS analysis (Fig. 1E and F), as well as an increase in the number of $\mathrm{CD} 14^{+}$cells by immunohistochemistry in cirrhosis compared to controls, was detected (Fig. 1G and H). The numbers of CD11c (a dendritic marker) positive cells were not different between the groups (Appendix I), demonstrating an overall predominance of $\mathrm{CD} 8^{+}$intestinal macrophages over $\mathrm{CD}_{11 \mathrm{c}^{+}}$dendritic cells. There were no differences in the groups regarding CD16, TLR-2, TLR-4, CD80, and CD86 surface expression.

Transcriptional analysis shows increased expression of IL-8, CCL2, CCL13, and iNOS

To analyse the transcriptional profile of the intestinal mucosa, we assessed a panel of 84 inflammatory genes. Using semi-quantitative RT-PCR, we identified upregulation of $I L-8, C C L 2, C C L 13$, and $i N O S$, and TLR 1, 2, 6. Final qRT-PCR confirmed upregulation $(>2$ fold) of four genes: IL-8, CCL2, CCL13, and iNOS (Table 2) ( Appen$\operatorname{dix} J$ ).

Increased levels of IL-8, CCL2, CCL13, and IL-6 are detected in the serum or supernatant of whole biopsy cultures

We assessed the significance of increased duodenal mRNA expression of $I L-8, C C L 2$, and CCL13, by determining the levels of these cytokines, as well as IL-6, in serum and supernatant of whole biopsy cultures. We detected increased levels of IL-6, IL-8, and CCL13 in the serum (Fig. 2A-C) and increased levels of IL-6, IL-8, and CCL2/MCP-1 in the supernatant of the biopsy cultures (Fig. 2D-F).

Immunohistochemistry shows increased iNOS synthesis and increased NO levels are detected in short-term duodenal biopsy cultures

To assess the relevance of increased iNOS mRNA at the transcriptional level, we assessed iNOS protein by immunohistochemistry and NO levels in the culture supernatant. There was a significant increase in the number of iNOS ${ }^{+}$cells in both decompensated and compensated cirrhosis compared to controls $(91.2 \pm 14.44$ vs. 54.4 $\pm 9.82 p<0.01 ; 83.2 \pm 12.68$ vs. $54.4 \pm 9.82 p<0.01$ ) (Fig. $3 \mathrm{~A}$ and $\mathrm{B}$ ). In addition, increased NO levels were detected in culture supernatant in decompensated cirrhosis. Co-culturing intestinal biopsies with LPS did not further increase NO levels (Fig. 3C).

\section{CD14 positive cells co-express iNOS}

Intestinal macrophages that express innate response receptors, such as $\mathrm{CD} 14^{+}$and TREM-1, have been associated with inflammation and the release of pro-inflammatory cytokines. Co-localisation studies confirmed that all $\mathrm{CD}_{1} 4^{+}$cells were iNOS positive (Appendix K). Therefore, the presence of $\mathrm{CD}_{14}{ }^{+}$iNOS $^{+}$macrophages that express iNOS and secrete NO confirms the presence of classically activated intestinal macrophages in cirrhosis.

Immunohistochemistry shows co-localisation of IL-6 and IL-8 in $\mathrm{CD}^{+} 8^{+}$and $\mathrm{NNOS}^{+}$macrophages

Inflammatory cytokines detected by gene expression analysis may be synthesized and released by epithelial and/or inflamma- 
Table 1. Clinical characteristics of the study population.

\begin{tabular}{|c|c|c|c|}
\hline Variable & $\begin{array}{l}\text { Control } \\
(n=19)\end{array}$ & $\begin{array}{l}\text { Compensated } \\
(\mathrm{n}=15)\end{array}$ & $\begin{array}{l}\text { Decompensated } \\
(n=29)\end{array}$ \\
\hline Age (yr) & $63 \pm 10$ & $57 \pm 10$ & $60 \pm 10$ \\
\hline Sex, male (\%) & 37 & 40 & 62 \\
\hline $\begin{array}{l}\text { Etiology } \\
\text { Alcoholic } \\
\text { NASH }\end{array}$ & - & $\begin{array}{l}3 \\
12\end{array}$ & $\begin{array}{l}19 \\
10\end{array}$ \\
\hline Child-Turcotte-Pugh score & 5 & $5.5(5-7)$ & $9.1(7-11)$ \\
\hline Child-Turcotte-Pugh score (A/B/C) & - & $(13 / 2 / 0)$ & $(0 / 14 / 15)$ \\
\hline MELD score & - & $6(4-7)$ & $17(7-31)$ \\
\hline Serum albumin (g/L) & $3.5 \pm 0.28^{*}$ & $3.6 \pm 0.57^{\dagger}$ & $2.8 \pm 0.44^{\star \dagger}$ \\
\hline INR & $1.1 \pm 0.22^{*}$ & $1.1 \pm 0.08^{\dagger}$ & $1.6 \pm 0.42^{* \dagger}$ \\
\hline Serum bilirubin (mg/dl) & $0.78 \pm 0.38^{*}$ & $0.99 \pm 0.41^{\dagger}$ & $5.19 \pm 3.47^{*+}$ \\
\hline Platelets (10\%/L) & $277.06 \pm 83.29^{\star}$ & $156.33 \pm 69.56 \bullet \bullet$ & $103.74 \pm 55.04^{\star \dagger}$ \\
\hline White cell count (10\%/L) & $6.08 \pm 2.30$ & $4.63 \pm 2.23$ & $7.13 \pm 4.45$ \\
\hline Positive blood culture (n (\%)) & - & 0 & $3(10)$ \\
\hline Ascites (n (\%)) & - & 0 & $29(100)$ \\
\hline Variceal bleeding (n (\%)) & - & 0 & $3(10)$ \\
\hline Encephalopathy (n (\%)) & - & 0 & $8(28)$ \\
\hline Esophageal varices, $\mathrm{N}$ (small/large) & - & $7(4 / 3)$ & $25(10 / 15)$ \\
\hline
\end{tabular}

Child-Turcotte-Pugh score is represented as mean and range.

Other results are expressed as mean $\pm \mathrm{SD}$.

INR, international normalized ratio.

${ }^{*} p<0.05$ : Decompensated $v$ s. Controls.

- $p<0.05$ : Compensated vs. Controls.

${ }^{\dagger} p<0.05$ : Decompensated vs. Compensated.

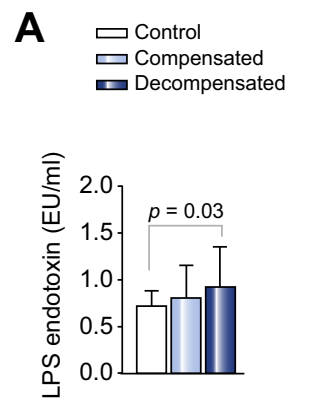
B $\square$ Control
$\square$ Compensated
Decompensated
$p<0.01$
C $\square$ Control
$\square$ Compensated
$\exists$ Decompensated

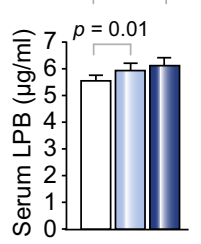

D

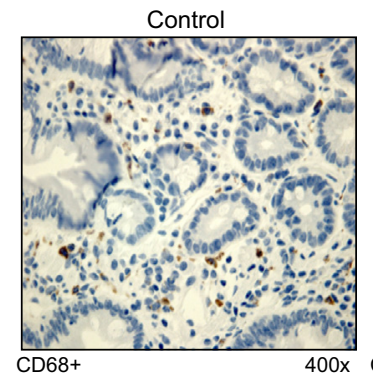

Decompensated

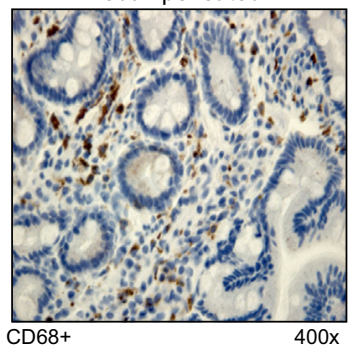

$\begin{array}{ll}\text { E } & \text { Control } \\ & \text { Compensated } \\ & \text { Decompensated }\end{array}$

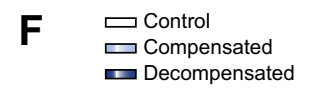

G

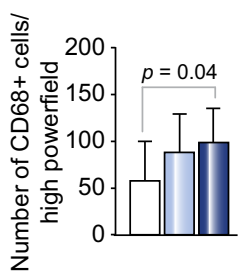

G $\underset{\substack{\text { Control } \\ \text { Decompensated }}}{\text { Decompated }}$
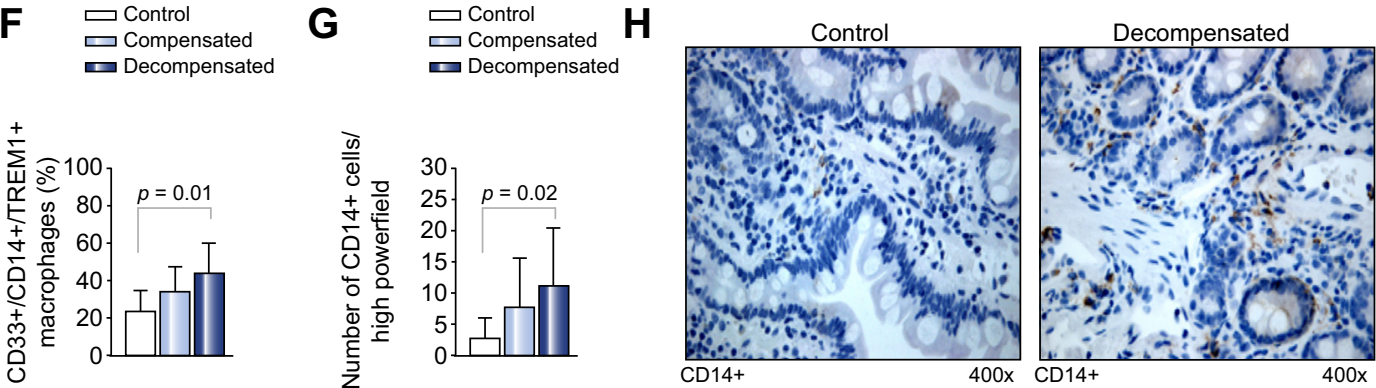

Fig. 1. Intestinal macrophages in decompensated cirrhosis display an activated phenotype. (A and B) Serum LPS and LBP levels were significantly elevated in decompensated but not in compensated cirrhosis or controls. (C and D) Immunohistochemistry showed an increase in CD68+ cells in decompensated cirrhosis compared to controls. (E and F) The frequency of CD33+/CD14+/Trem-1+ intestinal macrophages, assessed by flow cytometry, was significantly increased in decompensated cirrhosis compared to controls. (G and H) An increase in CD14+ cells was confirmed by immunohistochemistry. (This figure appears in color on the web.) 
Table 2. Genes upregulated in decompensated cirrhosis compared to controls.

\begin{tabular}{lll}
\hline Gene symbol & Fold regulation & $p$ value \\
\hline NOS2/iNOS & 2.69 & $0.04^{*}$ \\
CCL2 & 2.57 & $<0.01^{*}$ \\
CCL13 & 4.35 & $<0.01^{*}$ \\
IL8 & 2.84 & $0.02^{*}$ \\
\hline
\end{tabular}

${ }^{*}$ Genes significantly upregulated (fold changes $>2$ and $p$ value $<0.05$ ) in decompensated cirrhosis compared to controls.

\section{A}

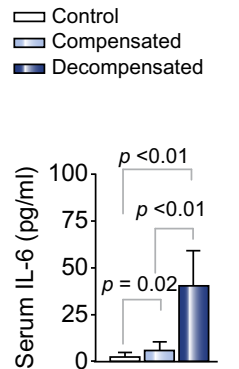

D

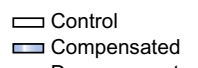

E. Decompensated

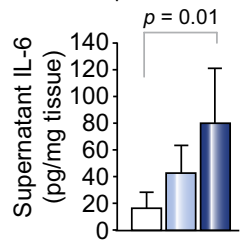

B

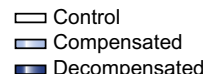

E.w Decompensated

$$
p<0.01
$$

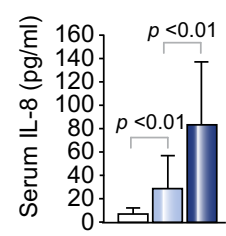

E

$\square$ Control

$\square$ Compensated

m Decompensated

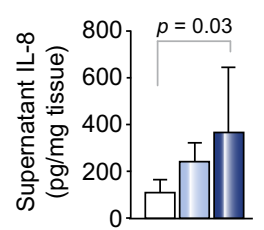

C

$\simeq$ Control

$\square$ Compensated

Decompensated

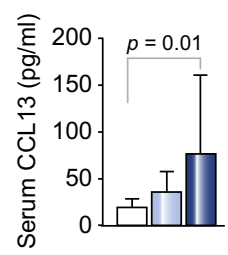

$\mathbf{F}$

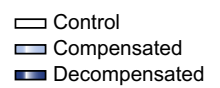

m Decompensated

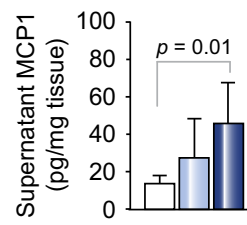

Fig. 2. Pro-inflammatory cytokine and chemokine levels are elevated in patients with decompensated cirrhosis. (A-C) Significantly increased IL-6, IL-8, and CCL13 levels were detected in the serum of compensated and decompensated cirrhosis patients compared to controls. (D-F) In addition, significantly increased IL-6, IL-8, and CCL2/MCP-1 levels were detected in the supernatant of short-term biopsy cultures in decompensated cirrhosis.

tory cells. We confirmed increased numbers of IL-6 positive cells in decompensated cirrhosis (Appendix L) and co-localisation of IL-6 with iNOS and CD68 in activated macrophages, indicating that macrophages are the major source of intestinal IL- 6 released in cirrhosis (Fig. 3D). IL-8 co-localised in iNOS+ cells, but only in a subpopulation of CD68+ cells, indicating that IL-8 is also produced by other inflammatory cells. (Fig. 3D). IL-6 was predominantly present in CD11c negative cells, indicating that dendritic cells are not the main cell source of this pro-inflammatory cytokine (Appendix M).

The epithelial barrier in cirrhosis is structurally normal but functionally altered

Morphological assessment of the epithelial barrier by TEM demonstrated no difference in inter-epithelial junctions between the

groups (Fig. 4A). Functional analysis showed a reduced TEER $\left(17.0 \pm 0.8\right.$ vs. $\left.21.4 \pm 1.1 \Omega . \mathrm{cm}^{2}, p=0.005\right)$ and higher passage of FITC-dx4 (43.1 \pm 3.5 vs. $31.2 \pm 2.4$ pmol, $p=0.013$ ) (Fig. 4B) in cirrhosis compared to controls, indicating an impaired duodenal barrier function, even after correcting for age $(p=0.009$ and $p=0.020$, respectively).

The structural TJ proteins ZO-1, Occludin, and Claudin-1, and the gap junction protein Connexion-43 were not different at the mRNA and protein levels between the groups (Fig. 4C). However, increased Claudin-2 levels were observed by Western blot and IHC documented a vesicular staining pattern on the apical pole of epithelial cells in decompensated cirrhosis (Fig. 4D and E). A trend towards lower ZO-1 protein levels not reaching statistical significance was observed in decompensated liver cirrhosis $(p=$ 0.052) (Appendix N).

\section{Discussion}

Bacterial infections commonly occur in end-stage liver disease, impacting on the natural history of cirrhosis, increasing the risk of variceal bleeding and decreasing survival [3]. Several lines of evidence support gut derived bacterial translocation being of particular importance [3,15-17]. However, the reason why the intestinal barrier fails in cirrhosis, and the molecular events at the gut wall associated with translocation remain poorly understood. In this study, we have shown that intestinal macrophages in cirrhosis have an activated phenotype and are responsible for the expression of iNOS and the secretion of NO and IL-6.

Various studies have confirmed that the bacterial flora is altered and intestinal permeability increased in cirrhosis $[18,19]$. However, it remains unclear if increased intestinal per-meability to macromolecules demonstrated in these studies, actually infers a barrier defect to bacterial products, including viable organisms. In order to understand the complex interaction between the epithelial barrier, inflammation and bacterial trans-location, we assessed the phenotype of intestinal macrophages, gene expression profiles and intestinal barrier function in compensated and decompensated cirrhosis.

LPS and LBP levels, used as surrogate markers of bacterial translocation, were significantly elevated in decompensated cirrhosis. We showed that intestinal macrophages in cirrhosis have an activated phenotype expressing innate immune receptors for LPS (CD14) and Trem-1. In addition, iNOS was upregulated at the mRNA and protein level, with higher numbers of iNOS $^{+}$activated macrophages observed histologically, in both decompensated and compensated cirrhosis. When functionally characterized, increased NO levels were detected in biopsy cultures in decompensated cirrhosis. Furthermore, macrophage activation preceded decompensation as iNOS ${ }^{+}$intestinal macrophages were detected in patients with compensated cirrhosis. This suggests that intestinal macrophage activation occurs early in cirrhosis and may already reflect responses to altered bacterial flora and increased events of bacterial translocation.

The significance of activated intestinal CD14 $4^{+}$Trem- $1^{+}$iNOS $^{+}$ macrophages in decompensated cirrhosis is of particular importance. Intestinal macrophages mostly lack CD14 and Trem-1 and are inert to microbial stimuli, LPS induced cytokine, and iNOS production [8]. In contrast, activated CD14 ${ }^{+}$Trem- $1^{+}$macrophages in IBD [20] respond to microbial stimulation, produce high levels of inflammatory cytokines (IFN- $\gamma$ IL-23, IL-1 $\beta$ ), and secrete IL-8, 
A

iNOS+
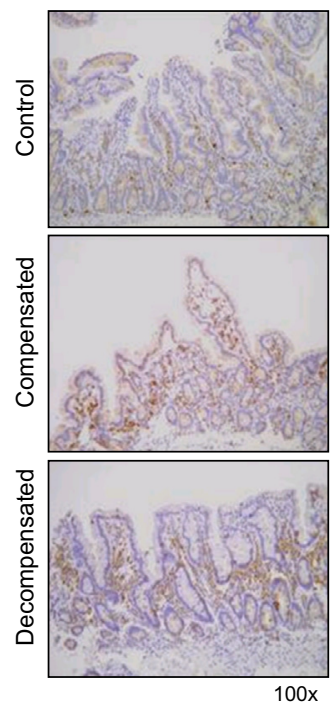

B

Control
Compensated

Decompensated

$p<0.01$
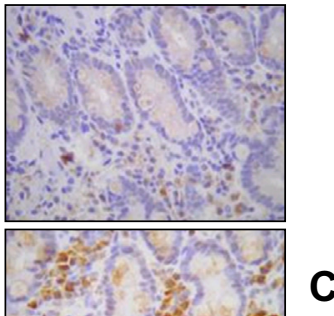

C

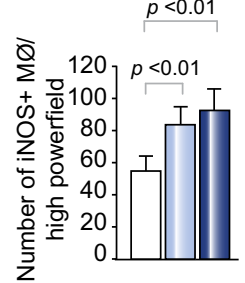

Control

$\square$ Compensated

Decompensated
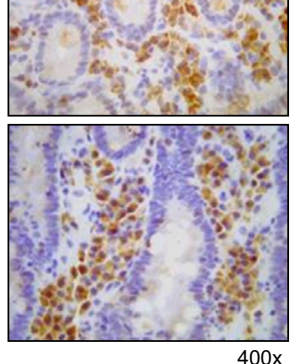

D

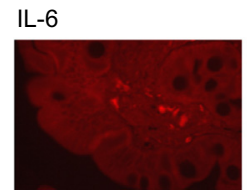

iNOS

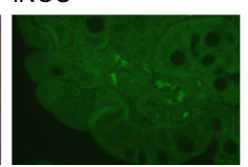

Merge

IL-6

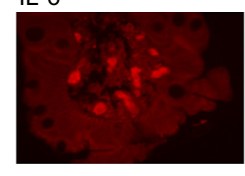

CD68

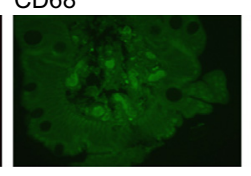

IL-8

iNOS

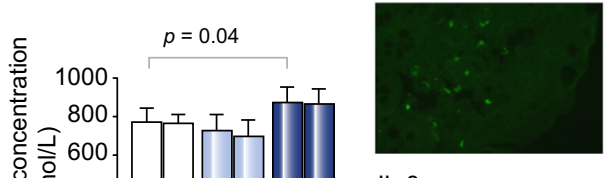

IL-8

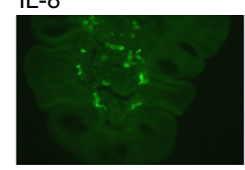

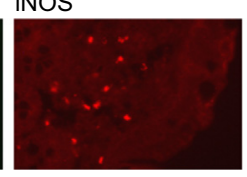

CD68

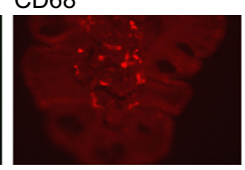

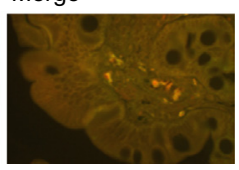

Merge

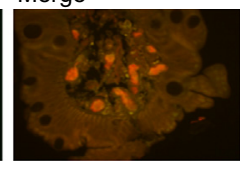

Merge

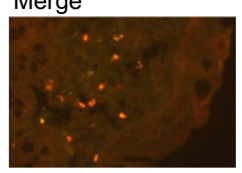

Merge

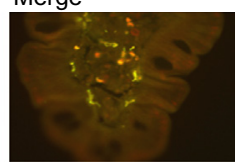

Fig. 3. iNOS+ cells that release NO and co-localise pro-inflammatory cytokines are increased in the duodenum of patients with cirrhosis. (A and B) A significant increase in the number of iNOS+ macrophages (MØ) was observed in compensated and decompensated cirrhosis compared to controls. (C) Increased NO levels were detected in the supernatant after short-term biopsy culture in decompensated cirrhosis. (D) Additional co-expression analysis of CD68+ iNOS+ and IL-6 showed that activated intestinal macrophages are the major source of IL- 6 released in cirrhosis. IL- 8 co-localised in iNOS+ cells, but only in a subpopulation of CD68+ cells, indicating that IL-8 is also produced by other inflammatory cells. (This figure appears in color on the web.)

A

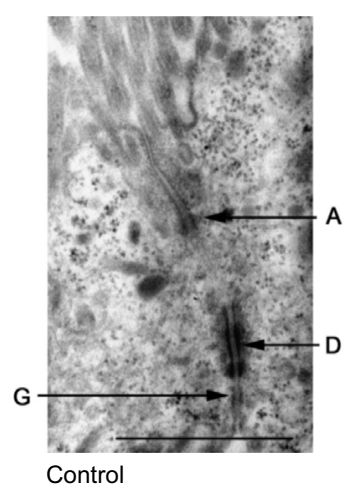

B

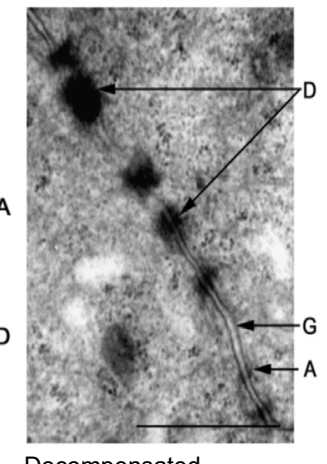

$\mathbf{E}$
- Control
- NASH/ASH cirrhosis
C 1. Control
2. Compensated
3. Decompensated
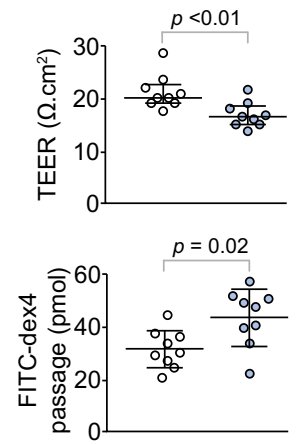

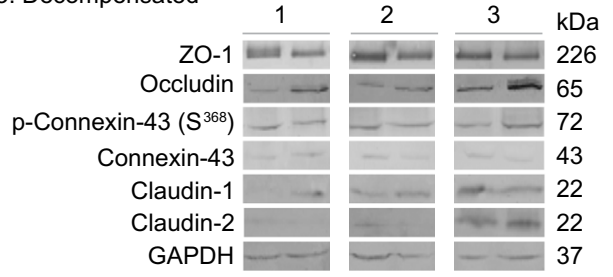

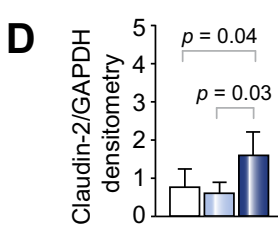

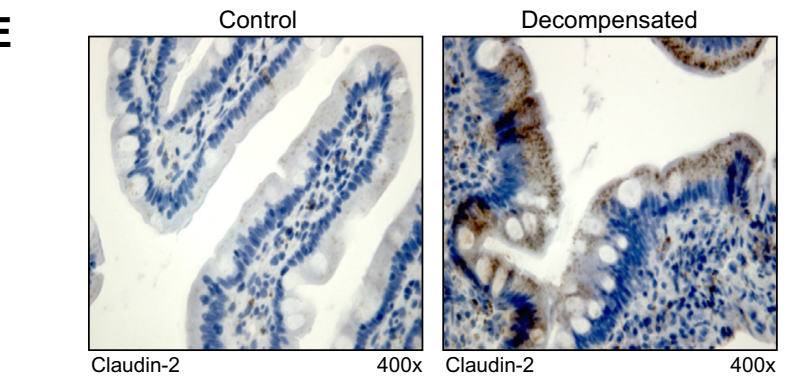

Fig. 4. The epithelial barrier is functionally altered in cirrhosis. (A) TEM showed an intact epithelial barrier in decompensated cirrhosis with no differences observed in (A) adherent junctions, (D) desmosomes or (G) gap junctions between the groups. Scale bars, $1 \mu \mathrm{m}$. (B) Functional assessment of the duodenal barrier showed reduced TEER and higher passage of FITC-dx4 in cirrhosis, indicating an impaired barrier function. (C-E) Representative Western blot analysis of TJ proteins showed increased Claudin-2 levels in decompensated cirrhosis, confirmed by densitometry. (C) No differences were seen in the TJ protein expression of Occludin, Claudin-1, Connexin-43, phosphorylated connexin-43, and ZO-1. (This figure appears in color on the web.) 
CCL2/MCP-1, which may be important in the pathogenesis of Cro-hn's disease $[10,21]$.

Despite the presence of activated intestinal macrophages in cirrhosis, an attenuated cytokine response was observed compared to other inflammatory states. In cirrhosis, in addition to increased iNOS mRNA, upregulation of genes associated with inflammatory cell and monocyte recruitment, including IL-8, CCL2, and CCL13, was observed at the transcriptional and protein levels and increased IL-6, IL-8, and CCL13 levels were detected in the serum of cirrhotic patients.

Increased expression of IL-8 by endothelial cells can be induced in culture by endotoxin [22], and IL-8 production is increased by Escherichia coli in Crohn's disease [23], suggesting that increased IL- 8 observed at the transcriptional and protein levels in cirrhosis, is indeed in response to bacterial products. Similarly, Trem $-1^{+}$macrophages and intestinal epithelial cells have been shown to be major sources of IL-6 in Crohn's disease, and elevated IL- 6 levels have been demonstrated in serum and tissue of IBD patients. Recently, it was shown that IL-6 regulates Claudin-2 expression and permeability in cultured intestinal epithelial cells, establishing a clear link between localised inflammation and intestinal permeability [7]. In our study, we could indeed confirm that activated intestinal macrophages were the major source of IL-6 and NO in cirrhosis, suggesting that these cells may be capable of producing factors that influence intestinal permeability.

Interestingly, TNF $\alpha$ was not different at the mRNA, immunohistochemical, culture or serum levels between the groups, and no activation of pathways associated with TLR4-mediated signalling (MyD88, p38MAPK, TRAF, NFKB) was observed, suggesting that increased iNOS expression is mediated by a TLR-independent mechanism. This is in contrast to a murine model of cholestatic liver disease where bacterial translocation was dependent on TLR-2 and TNFRI pathways, suggesting that the bile duct ligation model differs from molecular pathways associated with bacterial translocation in human non-cholestatic cirrhosis [24].

The intestinal epithelial barrier is a complex semi-permeable structure allowing active transcellular and passive paracellular absorption, but preventing bacterial translocation [4]. However, translocation may result when the epithelial layer is compromised or if paracellular permeability is altered so that bacterial products cross. The epithelial barrier, however, is particularly resilient and is maintained even when excessive epithelial loss occurs [25]. Paracellular permeability is mainly a function of TJ proteins $[5,6]$.

We showed that the TJ barrier was normal when assessed at the ultrastructural level and confirmed that the expression of the structural TJ and gap junction proteins was not altered at the transcriptional or protein levels in cirrhosis. However, when the epithelial barrier was functionally assessed, we demonstrated decreased TEER, increased permeability to a $4 \mathrm{kDa}$ paracellular probe and confirmed that Claudin-2, a known pore forming $\mathrm{TJ}$ protein, was significantly increased at the protein level in decompensated cirrhosis, suggesting that it is responsible for the increased permeability observed. Indeed, epithelial barrier dysfunction and elevated Claudin-2 expression associated with bacterial translocation have been observed in other diseases, such as Crohn's disease [26] and HIV infection [27]. Despite demonstrating increased permeability, it remains unclear to what extent Claudin-2 induced pore formation allows crossing of large bacterial products such as LPS and DNA.
The interaction of bacterial products with intestinal macrophages in regulating $\mathrm{TJ}$ protein turnover and permeability remains unknown. Enteric pathogens [28] and LPS have been shown to activate iNOS [12]. Endotoxin administered to wild type mice impaired gut barrier function [29], and induced bacterial translocation to mesenteric lymph nodes [30]. Pharmacological inhibition with selective iNOS inhibitors, or genetic ablation $\left(\right.$ iNOS $^{-1-}$ ) prevented LPS induced epithelial barrier dysfunction and bacterial translocation [29,30]. In addition, activated macrophages secreting NO in epithelial co-cultures inhibited connexion-43 mediated epithelial barrier repair [12]. Collectively, these studies demonstrate that macrophage activation by altered bacterial populations or LPS may profoundly affect NO synthesis, $\mathrm{TJ}$ regulation, and bacterial translocation.

Due to ethical considerations, our study included only patients with cirrhosis at the time of screening for varices. It is possible that an even more pronounced inflammatory response may be observed, due to the more extensive bacterial burden, in the distal gastrointestinal tract. Further studies should assess bacterial translocation in the colon, phagocytic activity of intestinal macrophage populations in cirrhosis, and the effect of lactulose, norfloxacin, and rifaximin on $\mathrm{CD}_{1} 4^{+}$intestinal populations.

In summary, our study demonstrated that intestinal macrophages in cirrhosis have a distinct phenotype similar to other inflammatory states. These CD $14^{+}$Trem $-1^{+}$macrophages express iNOS and secrete NO and are the main cell source of cytokines/ chemokines, associated with inflammatory cell recruitment. In addition, iNOS ${ }^{+}$macrophages accumulated early in compensated cirrhosis before the onset of decompensation. Increased duodenal IL-6, NO, and Claudin-2 levels strongly suggest that these factors enhance intestinal permeability to bacterial products in patients with decompensated cirrhosis with ascites.

\section{Financial support}

Johannie du Plessis and Schalk van der Merwe are both recipients of the South African Gastroenterological Society (SAGES)/Astra Zeneca fellowship.

\section{Conflict of interest}

The authors who have taken part in this study declared that they do not have anything to disclose regarding funding or conflict of interest with respect to this manuscript.

\section{References}

[1] Arvaniti V, D’Amico G, Fede G, Manousou P, Tsochatzis E, Pleguezuelo M et al. Infections in patients with cirrhosis increase mortality four-fold and should be used in determining prognosis. Gastroenterology 2010;139: 1246-1256.

[2] Zapater P, Francés R, González-Navajas JM, de la Hoz MA, Moreu R, Pascual S, et al. Serum and ascitic fluid bacterial DNA: a new independent prognostic 
factor in noninfected patients with cirrhosis. Hepatology 2008;48: 1924-1931.

[3] Bellot P, García-Pagán JC, Francés R, Abraldes JG, Navasa M, Perez-Mateo M, et al. Bacterial DNA translocation is associated with systemic circulatory abnormalities and intrahepatic endothelial dysfunction in patients with cirrhosis. Hepatology 2010;52:2044-2052.

[4] Turner JR. Intestinal mucosal barrier function in health and disease. Nat Rev Immunol 2009;9:799-809.

[5] Marchiando AM, Graham WV, Turner JR. Epithelial barriers in homeostasis and disease. Annu Rev Pathol 2010;5:119-144.

[6] John LJ, Fromm M, Schulzke JD. Epithelial barriers in intestinal inflammation. Antioxid Redox Signal 2011;15:1255-1270.

[7] Suzuki T, Yoshinaga N, Tanabe S. IL-6 regulates claudin-2 expression and tight junction permeability in intestinal epithelium. J Biol Chem 2011;286: 31263-31271.

[8] Smythies LE, Sellers M, Clements RH, Mosteller-Barnum M, Meng G, Benjamin $\mathrm{WH}$, et al. Human intestinal macrophages display profound inflammatory anergy despite avid phagocytic and bacteriocidal activity. J Clin Invest 2005;115:66-75.

[9] Smith PD, Smythies LE, Shen R, Greenwell-Wild T, Gliozzi M, Wahl SM. Intestinal macrophages and response to microbial encroachment. Mucosal Immunol 2011;4:31-42.

[10] Kamada N, Hisamatsu T, Okamoto S, Chinen H, Kobayashi T, Sato T, et al. Unique CD14+ intestinal macrophages contribute to the pathogenesis of Crohn disease via IL-23/IFN- $\gamma$ axis. J Clin Invest 2008;118:2269-2280.

[11] Leaphart CL, Qureshi F, Cetin S, Li J, Dubowski T, Batey C, et al. Interferon- $\gamma$ inhibits intestinal restitution by preventing gap junction communication between enterocytes. Gastroenterology 2007;132:2395-2411.

[12] Anand RJ, Dai S, Rippel C, Leaphart C, Qureshi F, Gribar SC, et al. Activated macrophages inhibit enterocyte gap junctions via the release of nitric oxide. Am J Physiol Gastrointest Liver Physiol 2008;294:G109-G119.

[13] Cassol E, Malfeld S, Mahasha P, van der Merwe S, Cassol S, Seebregts C, et al Persistent microbial translocation and immune activation in HIV-1-infected South Africans receiving combination antiretroviral therapy. J Infect Dis 2010;202:723-733.

[14] Wallon C, Braaf Y, Wolving M, Olaison G, Söderholm JD. Endoscopic biopsies in Ussing chambers evaluated for studies of macromolecular permeability in the human colon. Scand J Gastroenterol 2005;40:586-595.

[15] Sandler NG, Koh C, Roque A, Eccleston JL, Siegel RB, Demino M, et al. Host response to translocated microbial products predicts outcomes of patients with HBV or HCV infection. Gastroenterology 2011;141:1220-1230.

[16] Guarner C, González-Navajas JM, Sánchez E, Soriando G, Frances R, Chiva M, et al. The detection of bacterial DNA in blood of rats with CCl4-induced cirrhosis with ascites represents episodes of bacterial translocation. Hepatology 2006;44:633-639.
[17] Fernández J, Navasa M, Planas R, Montoliu S, Monfort D, Soriano G, et al. Primary prophylaxis of spontaneous bacterial peritonitis delays hepatorenal syndrome and improves survival in cirrhosis. Gastroenterology 2007;133: 818-824.

[18] Riordan SM, Williams R. The intestinal flora and bacterial infection in cirrhosis. Hepatology 2006;45:744-757.

[19] Yang R, Harada T, Li J, Uchiyama T, Han Y, Englert JA, et al. Bile modulates intestinal epithelial barrier function via an extracellular signal related kinase 1/2 dependent mechanism. Intensive Care Med 2005;31:709-717.

[20] Schenk M, Bouchon A, Seibold F, Mueller C. Trem-1 expressing intestinal macrophages crucially amplify chronic inflammation in experimental colitis and inflammatory bowel diseases. J Clin Invest 2007;117:3097-3106.

[21] Sheikh SZ, Matsuoka K, Kobayashi T, Li F, Rubinas T, Plevy SE. Cutting edge: IFN- $\gamma$ is a negative regulator of IL-23 in murine macrophages and experimental colitis. J Immunol 2010;184:4069-4073.

[22] Anand AR, Cucchiarini M, Terwilliger EF, Ganju RK. The tyrosine kinase Pyk2 mediates lipopolysaccharide-induced IL-8 expression in human endothelial cells. J Immunol 2008;180:5636-5644.

[23] Martin HM, Campbell BJ, Hart CA, Mpofu C, Nayar M, Singh R, et al. Enhanced Escherichia coli adherence and invasion in Crohn's disease and colon cancer. Gastroenterology 2004;127:80-93.

[24] Hartmann P, Haimerl M, Mazagova M, Brenner DA, Schnabl B. Toll-like receptor 2-mediated intestinal injury and enteric tumor necrosis factor receptor I contribute to liver fibrosis in mice. Gastroenterology 2012;143: 1330-1340.

[25] Marchiando AM, Shen L, Graham WV, Edelblum KL, Duckworth CA, Guan Y, et al. The epithelial barrier is maintained by in vivo tight junction expansion during pathologic intestinal epithelial shedding. Gastroenterology 2011;140:1208-1218.

[26] Zeissig S, Bürgel N, Günzel D, Richter J, Mankertz J, Wahnschaffe U, et al. Changes in expression and distribution of claudin 2, 5 and 8 lead to discontinuous tight junctions and barrier dysfunction in active Crohn's disease. Gut 2007;56:61-72.

[27] Smith AJ, Schacker TW, Reilly CS, Haase AT. A role for syndecan-1 and claudin-2 in microbial translocation during HIV-1 infection. J Acquir Immune Defic Syndr 2010;55:306-315.

[28] Resta-Lenert S, Barrett KE. Enteroinvasive bacteria alter barrier and transport properties of human intestinal epithelium: role of iNOS and COX-2. Gastroenterology 2002;122:1070-1087.

[29] Han X, Fink MP, Yang R, Delude RL. Increased iNOS activity is essential for intestinal epithelial tight junction dysfunction in endotoxemic mice. Shock 2004;21:261-270.

[30] Mishima S, Xu D, Lu Q, Deitch EA. Bacterial translocation is inhibited in inducible nitric oxide synthase knockout mice after endotoxin challenge but not in a model of bacterial overgrowth. Arch Surg 1997;132:1190-1195. 


\section{Supplementary text:}

\section{Appendix A}

Supplementary Table 1: Summary of the total number of samples included in each investigation

\begin{tabular}{lccc}
\hline Experimental procedure & Decompensated & Compensated & Control \\
\hline $\begin{array}{l}\text { Total number of patients } \\
\text { included }\end{array}$ & $\mathrm{n}=29$ & $\mathrm{n}=15$ & $\mathrm{n}=19$ \\
Plasma LPS determination & $\mathrm{n}=25$ & $\mathrm{n}=14$ & $\mathrm{n}=19$ \\
Plasma cytokine determination & $\mathrm{n}=16$ & $\mathrm{n}=13$ & $\mathrm{n}=17$ \\
Flow cytometry & $\mathrm{n}=22$ & $\mathrm{n}=10$ & $\mathrm{n}=12$ \\
Gene expression analysis & $\mathrm{n}=27$ & $\mathrm{n}=11$ & $\mathrm{n}=14$ \\
Histology - CD68 & $\mathrm{n}=21$ & $\mathrm{n}=11$ & $\mathrm{n}=7$ \\
Histology - iNOS & $\mathrm{n}=13$ & $\mathrm{n}=11$ & $\mathrm{n}=11$ \\
IHC & $\mathrm{n}=14$ & $\mathrm{n}=11$ & $\mathrm{n}=6$ \\
Western blot- REST & $\mathrm{n}=10$ & $\mathrm{n}=4$ & $\mathrm{n}=6$ \\
Western blot - ZO-1 & $\mathrm{n}=4$ & $\mathrm{n}=4$ & $\mathrm{n}=3$ \\
Biopsy cultures & $\mathrm{n}=10$ & $\mathrm{n}=5$ & $\mathrm{n}=7$ \\
$\begin{array}{l}\text { Supernatant cytokine } \\
\text { determination }\end{array}$ & $\mathrm{n}=7$ & $\mathrm{n}=4$ & $\mathrm{n}=5$ \\
Supernatant total nitrite analysis & & & \\
\hline
\end{tabular}




\section{Appendix B}

\section{Preparation of single cell suspension from duodenal biopsies for flow cytometry}

A single-cell suspension was obtained by means of GentleMACS dissociator (MiltenyiBiotec, Gladbach, Germany). Duodenal biopsies were digested in RPMI 1640 containing 1.0 mg/ml collagenase type IV (Sigma, St. Louis, MO) at $37^{\circ} \mathrm{C}$ for $30 \mathrm{~min}$. The single cell suspension was then passed through a $70-\mu \mathrm{m}$ cell strainer and washed in sterile PBS with $0.5 \%$ BSA (PEB buffer).

\section{Appendix C}

\section{Flow cytometry analysis - determination of macrophage phenotype}

The phenotype of intestinal macrophages was determined assessing a panel of surface markers characteristic of monocyte/macrophage lineage (CD33), activation status (CD14, CD16, Trem-1), and co-stimulatory molecules (CD80, CD86). In addition we assessed the surface expression of the toll-like receptor 2 and 4 (TLR-2, and 4). Single cell preparations in PEB buffer were stained with $20 \mu \mathrm{l}$ monoclonal antibodies (Mabs)/ $100 \mu \mathrm{l}$ of $10^{6}$ cells, incubated for $20 \mathrm{~min}$ at room temperature in the dark. The Mabs were used in two-colour combinations as follows: CD14-PE-Cy7 with CD33-APC; CD16-FITC with TREM-1-PE; CD80 (B7-1)-FITC, with CD86 (B7-2)-PE; TLR-2-FITC with TLR-4-PE-Cy7. Samples were processed for analysis in the Beckman Coulter TQ-Prep system. For accurate counting, 100 $\mu$ l of Flow-Count ${ }^{\mathrm{TM}}$ Fluorospheres (Beckman Coulter, Miami, FL, USA), was added. Cells were then analysed by flow cytometry on the Beckman Coulter Cytomics FC500 cytometer fitted with a $488 \mathrm{~nm}$ blue laser and a $635 \mathrm{~nm}$ solid-state red laser, using 2-colour protocols and the CXP Software (Beckman Coulter, Miami, FL, USA). The macrophage population within the total cell population was identified using orthogonal light scatter features, together with CD14, CD 33 and CD16 expression.

In addition, Composite File Analysis, using the KALUZA Flow Cytometry Analysis software (Beckman Coulter Inc, Miami, USA) was performed on the CD14 vs. CD33 and CD16 vs. 
TREM1 Histogram Files per sample, to assess the percentage of $\mathrm{CD} 14^{+} / \mathrm{CD}_{3} 3^{+}$coexpressing CD16 and/or TREM1.

Supplementary Table 2: Summary of antibodies used for Flow cytometry

\begin{tabular}{ll}
\hline Antibodies & Company \\
\hline CD14-PE-Cy7 & eBioscience, San Diego, California, USA \\
CD33-APC Siglec-3 & R\&D Systems, Minneapolis, USA \\
CD16-FITC & Beckman Coulter, Miami, FL, USA \\
TREM-1-PE & R\&D Systems, Minneapolis, USA \\
CD80 (B7-1)-FITC & R\&D Systems, Minneapolis, USA \\
CD86 (B7-2)-PE & eBioscience, San Diego, California, USA \\
TLR-2-FITC TL2.1 & eBioscience, California, USA \\
TLR-4-PE-Cy7 HTA125 & eBioscience, San Diego, USA \\
\hline
\end{tabular}




\section{Appendix D}

Supplementary Table 3: Genes included in the Human Inflammatory response and Autoimmunity PAHS-077A RT ${ }^{2}$ Profiler $^{\text {TM }}$ Array SABioscience, Frederick, MD, USA

\begin{tabular}{|c|c|c|}
\hline $\begin{array}{l}\text { Gene } \\
\text { symbol }\end{array}$ & GeneBank & Official full name \\
\hline$B C L 6$ & NM_001706 & B-cell CLL/lymphoma 6 \\
\hline C3 & NM_000064 & Complement component 3 \\
\hline C3AR1 & NM_004054 & Complement component 3a receptor 1 \\
\hline$C 4 A$ & NM_007293 & Complement component 4A (Rodgers blood group) \\
\hline CCL11 & NM_002986 & Chemokine (C-C motif) ligand 11 \\
\hline CCL13 & NM_005408 & Chemokine (C-C motif) ligand 13 \\
\hline CCL16 & NM_004590 & Chemokine (C-C motif) ligand 16 \\
\hline CCL17 & NM_002987 & Chemokine (C-C motif) ligand 17 \\
\hline CCL19 & NM_006274 & Chemokine (C-C motif) ligand 19 \\
\hline CCL2 & NM_002982 & Chemokine (C-C motif) ligand 2 \\
\hline CCL21 & NM_002989 & Chemokine (C-C motif) ligand 21 \\
\hline CCL22 & NM_002990 & Chemokine (C-C motif) ligand 22 \\
\hline CCL23 & NM_005064 & Chemokine (C-C motif) ligand 23 \\
\hline CCL24 & NM_002991 & Chemokine (C-C motif) ligand 24 \\
\hline CCL3 & NM_002983 & Chemokine (C-C motif) ligand 3 \\
\hline CCL4 & NM_002984 & Chemokine (C-C motif) ligand 4 \\
\hline CCL5 & NM_002985 & Chemokine (C-C motif) ligand 5 \\
\hline CCL7 7 & NM_006273 & Chemokine (C-C motif) ligand 7 \\
\hline CCL8 & NM_005623 & Chemokine (C-C motif) ligand 8 \\
\hline CCR1 & NM_001295 & Chemokine (C-C motif) receptor 1 \\
\hline CCR2 & $\begin{array}{l}\text { NM_00112339 } \\
6\end{array}$ & Chemokine (C-C motif) receptor 2 \\
\hline CCR3 & NM_001837 & Chemokine (C-C motif) receptor 3 \\
\hline CCR4 & NM_005508 & Chemokine (C-C motif) receptor 4 \\
\hline
\end{tabular}




\begin{tabular}{|c|c|c|}
\hline CCR7 & NM_001838 & Chemokine (C-C motif) receptor 7 \\
\hline$C D 40$ & NM_001250 & CD40 molecule, TNF receptor superfamily member 5 \\
\hline CD4OLG & NM_000074 & CD40 ligand \\
\hline$C E B P B$ & NM_005194 & CCAAT/enhancer binding protein (C/EBP), beta \\
\hline$C R P$ & NM_000567 & C-reactive protein, pentraxin-related \\
\hline CSF1 & NM_000757 & Colony stimulating factor 1 (macrophage) \\
\hline CXCL1 & NM_001511 & $\begin{array}{l}\text { Chemokine (C-X-C motif) ligand } 1 \text { (melanoma growth stimulating } \\
\text { activity, } \alpha)\end{array}$ \\
\hline CXCL10 & NM_001565 & Chemokine (C-X-C motif) ligand 10 \\
\hline CXCL2 & NM_002089 & Chemokine (C-X-C motif) ligand 2 \\
\hline CXCL3 & NM_002090 & Chemokine (C-X-C motif) ligand 3 \\
\hline CXCL5 & NM_002994 & Chemokine (C-X-C motif) ligand 5 \\
\hline CXCL6 & NM_002993 & $\begin{array}{l}\text { Chemokine (C-X-C motif) ligand } 6 \text { (granulocyte chemotactic protein } \\
\text { 2) }\end{array}$ \\
\hline CXCL9 & NM_002416 & Chemokine (C-X-C motif) ligand 9 \\
\hline CXCR4 & NM_003467 & Chemokine (C-X-C motif) receptor 4 \\
\hline FASLG & NM_000639 & Fas ligand (TNF superfamily, member 6 ) \\
\hline FLT3LG & NM_001459 & Fms-related tyrosine kinase 3 ligand \\
\hline FOS & NM_005252 & FBJ murine osteosarcoma viral oncogene homolog \\
\hline HDAC4 & NM_006037 & Histone deacetylase 4 \\
\hline IFNG & NM_000619 & Interferon, gamma \\
\hline IL 10 & NM_000572 & Interleukin 10 \\
\hline IL 10RB & NM_000628 & Interleukin 10 receptor, beta \\
\hline IL 18 & NM_001562 & Interleukin 18 (interferon-gamma-inducing factor) \\
\hline IL 18RAP & NM_003853 & Interleukin 18 receptor accessory protein \\
\hline IL $1 A$ & NM_000575 & Interleukin 1, alpha \\
\hline IL 1B & NM_000576 & Interleukin 1, beta \\
\hline IL $1 F 10$ & NM_173161 & Interleukin 1 family, member 10 (theta) \\
\hline IL $1 R 1$ & NM_000877 & Interleukin 1 receptor, type I \\
\hline IL $1 R A P$ & NM_002182 & Interleukin 1 receptor accessory protein \\
\hline IL $1 R N$ & NM_000577 & Interleukin 1 receptor antagonist \\
\hline
\end{tabular}




\begin{tabular}{|c|c|c|}
\hline IL22 & NM_020525 & Interleukin 22 \\
\hline IL22RA2 & NM_052962 & Interleukin 22 receptor, alpha 2 \\
\hline IL23A & NM_016584 & Interleukin 23 , alpha subunit p19 \\
\hline IL23R & NM_144701 & Interleukin 23 receptor \\
\hline IL6 & NM_000600 & Interleukin 6 (interferon, beta 2) \\
\hline IL6R & NM_000565 & Interleukin 6 receptor \\
\hline IL8 & NM_000584 & Interleukin 8 \\
\hline CXCR1 & NM_000634 & Chemokine (C-X-C motif) receptor 1 \\
\hline CXCR2 & NM_001557 & Chemokine ( $\mathrm{C}-\mathrm{X}-\mathrm{C}$ motif) receptor 2 \\
\hline IL9 & NM_000590 & Interleukin 9 \\
\hline ITGB2 & NM_000211 & Integrin, beta 2 (complement component 3 receptor 3 and 4 subunit) \\
\hline KNG1 & NM_000893 & Kininogen 1 \\
\hline$L T A$ & NM_000595 & Lymphotoxin alpha (TNF superfamily, member 1) \\
\hline$\angle T B$ & NM_002341 & Lymphotoxin beta (TNF superfamily, member 3) \\
\hline LY96 & NM_015364 & Lymphocyte antigen 96 \\
\hline MYD88 & NM_002468 & Myeloid differentiation primary response gene (88) \\
\hline NFATC3 & NM_004555 & $\begin{array}{l}\text { Nuclear factor of activated T-cells, cytoplasmic, calcineurin- } \\
\text { dependent } 3\end{array}$ \\
\hline NFKB1 & NM_003998 & Nuclear factor of kappa light polypeptide gene enhancer in B-cells 1 \\
\hline NOS2 & NM_000625 & Nitric oxide synthase 2 , inducible \\
\hline$N R 3 C 1$ & NM_000176 & $\begin{array}{l}\text { Nuclear receptor subfamily } 3 \text {, group C, member } 1 \text { (glucocorticoid } \\
\text { receptor) }\end{array}$ \\
\hline RIPK2 & NM_003821 & Receptor-interacting serine-threonine kinase 2 \\
\hline TIRAP & NM_00103966 & Toll-interleukin 1 receptor (TIR) domain containing adaptor protein \\
\hline TLR1 & NM_003263 & Toll-like receptor 1 \\
\hline$T L R 2$ & NM_003264 & Toll-like receptor 2 \\
\hline$T L R 3$ & NM_003265 & Toll-like receptor 3 \\
\hline$T L R 4$ & NM_138554 & Toll-like receptor 4 \\
\hline$T L R 5$ & NM_003268 & Toll-like receptor 5 \\
\hline$T L R 6$ & NM_006068 & Toll-like receptor 6 \\
\hline
\end{tabular}




$\begin{array}{lll}\text { TLR7 } & \text { NM_016562 } & \text { Toll-like receptor 7 } \\ \text { TNF } & \text { NM_000594 } & \text { Tumor necrosis factor } \\ \text { TNFSF14 } & \text { NM_003807 } & \text { Tumor necrosis factor (ligand) superfamily, member 14 } \\ \text { TOLLIP } & \text { NM_019009 } & \text { Toll interacting protein } \\ \text { B2M } & \text { NM_004048 } & \text { Beta-2-microglobulin } \\ \text { HPRT1 } & \text { NM_000194 } & \text { Hypoxanthine phosphoribosyltransferase 1 } \\ \text { RPL13A } & \text { NM_012423 } & \text { Ribosomal protein L13a } \\ \text { GAPDH } & \text { NM_002046 } & \text { Glyceraldehyde-3-phosphate dehydrogenase } \\ \text { ACTB } & \text { NM_001101 } & \text { Actin, beta }\end{array}$




\section{Appendix E}

Supplementary Table 4: Genes included in CAPH09859D customized RT $^{2}$ Profiler PCR array (SABioscience, Frederick, MD, USA)

\begin{tabular}{|c|c|c|}
\hline $\begin{array}{l}\text { Gene } \\
\text { Symbol }\end{array}$ & Refseq \# & Official Full Name \\
\hline TLR1 & NM_003263 & toll-like receptor 1 \\
\hline$T L R 2$ & NM_003264 & toll-like receptor 2 \\
\hline TLR4 & NM_138554 & toll-like receptor 4 \\
\hline TLR6 & NM_006068 & toll-like receptor 6 \\
\hline NOD1 & NM_006092 & nucleotide-binding oligomerization domain containing 1 \\
\hline NOD2 & NM_022162 & nucleotide-binding oligomerization domain containing 2 \\
\hline$T L R 9$ & NM_017442 & toll-like receptor 9 \\
\hline TIRAP & NM_001039661 & toll-interleukin 1 receptor (TIR) domain containing adaptor protein \\
\hline TRAF6 & NM_004620 & TNF receptor-associated factor 6 \\
\hline MAPK14 & NM_001315 & mitogen-activated protein kinase 14 \\
\hline MAPK1 & NM_002745 & mitogen-activated protein kinase 1 \\
\hline MAPK8 & NM_002750 & mitogen-activated protein kinase 8 \\
\hline JUN & NM_002228 & jun oncogene \\
\hline NFKB1 & NM_003998 & $\begin{array}{l}\text { nuclear factor of kappa light polypeptide gene enhancer in B-cells } \\
1\end{array}$ \\
\hline CEBPB & NM_005194 & CCAAT/enhancer binding protein (C/EBP), beta \\
\hline GJA1 & NM_000165 & gap junction protein, alpha 1 \\
\hline TJP1 & NM_175610 & tight junction protein 1 (zona occludens 1 ) \\
\hline CLDN1 & NM_021101 & claudin 1 \\
\hline CLDN2 & NM_020384 & claudin 2 \\
\hline OCLN & NM_002538 & occludin \\
\hline NOS2 & NM_000625 & nitric oxide synthase 2 , inducible \\
\hline CCL2 & NM_002982 & chemokine ( $\mathrm{C}-\mathrm{C}$ motif) ligand 2 \\
\hline CCL13 & NM_005408 & chemokine (C-C motif) ligand 13 \\
\hline
\end{tabular}




$\begin{array}{lll}\text { IL8 } & \text { NM_000584 } & \text { interleukin 8 } \\ \text { IL22 } & \text { NM_020525 } & \text { interleukin 22 } \\ \text { IL10 } & \text { NM_000572 } & \text { interleukin 10 } \\ \text { TGFB1 } & \text { NM_000660 } & \text { Transforming growth factor, beta 1 } \\ \text { RPL13A } & \text { NM_012423 } & \text { ribosomal protein L13a } \\ \text { B2M } & \text { NM_004048 } & \text { beta-2-microglobulin }\end{array}$




\section{Appendix F}

Histological analysis was conducted by a pathologist blinded to the subgroups on H\&Estained $3 \mu \mathrm{m}$ sections. Immunohistochemical stainings for iNOS, CD14, CD68, CD11c, IL6, IL8 and Claudin 2 were performed on tissue sections incubated with primary antibody treated with Envision ${ }^{\mathrm{TM}} / \mathrm{HRP}$ dual link polymer, visualized with diaminobenzidine chromogen and counter-stained with haematoxylin. Positive mononuclear inflammatory cells in five representative high power fields (magnification $\times 400$ ) were counted and reported as the average number of positive cells/HPF. In order to assess if all CD14 and CD68 positive cells co-localized with iNOS we performed double staining experiments with dye swap. Next we assessed co-localisation of CD68 and iNOS with IL6 and IL8 respectively. Finally we assessed whether CD11c positive dentritic cells also co-localized with IL-6. TEM was performed on Glutaraldehyde-fixed specimens placed in 1\% osmium tetraoxide, embedded in quetol resin, contrasted with uranyl acetate and lead citrate and analyzed on a JOEL JEM 2100F microscope. 


\section{Appendix G}

Supplementary Table 5: Reagents used in buffers for western blot analysis

\begin{tabular}{ll}
\hline Sample buffers for Western blot analysis & Company \\
\hline Zona occludens $\mathbf{1}(\mathbf{Z O}-\mathbf{1})$ protein & \\
\hline $50 \mathrm{mM}$ Tris-HCL, pH7.4 & Merck, New Jersey, USA \\
$50 \mathrm{mM} \mathrm{NaCl}$ & Merck, New Jersey, USA \\
$1 \mathrm{mM} \mathrm{DTT}$ & Sigma Chemical Co., St Louis, MO \\
$0.5 \%$ Tween-20 & Sigma Chemical Co., St Louis, MO \\
$1 \%$ N-larkosylsarkosine & Sigma Chemical Co., St Louis, MO \\
$1 \%$ SDS & Sigma Chemical Co., St Louis, MO \\
$1 \%$ Triton X-100 & Sigma Chemical Co., St Louis, MO
\end{tabular}

\section{Sample buffer for other tight junction proteins}

\begin{tabular}{ll}
\hline $50 \mathrm{mM}$ Tris-HCL, pH7.4 & Merck, New Jersey, USA \\
$100 \mu \mathrm{M} \mathrm{NaCl}$ & Merck, New Jersey, USA \\
$10 \mu \mathrm{M}$ EDTA, $50 \mu \mathrm{M} \mathrm{NaF}$ & Sigma Chemical Co., St Louis, MO \\
$500 \mu \mathrm{M} \mathrm{Na}_{3} \mathrm{VO}_{4}$ & Sigma Chemical Co., St Louis, MO \\
$1 \%$ Triton X-100 & Sigma Chemical Co., St Louis, MO \\
$1 \mathrm{Nm}$ PMSF & Sigma Chemical Co., St Louis, MO \\
$1 \mathrm{X}$ Protease inhibitor cocktail & Roche, Basel, Switzerland
\end{tabular}




\section{Appendix H}

\section{Ussing chamber experiments}

Modified 3ml Ussing chambers (Mussler Scientific Instruments, Aachen, Germany) were used to mount biopsies as described previously [14]. The mucosal compartment was filled with $3 \mathrm{ml}$ of $10 \mathrm{mM}$ mannitol in Krebs-Ringer bicarbonate buffer and the serosal compartment was filled with $3 \mathrm{ml}$ of $10 \mathrm{mM}$ glucose in Krebs-Ringer bicarbonate buffer. Solutions were kept at $37^{\circ} \mathrm{C}$ and continuously carbogenated with $\mathrm{O}_{2} / \mathrm{CO}_{2}(95 / 5 \%)$. Experiments were performed in open-circuit conditions and transmucosal potential difference was continuously monitored using $\mathrm{Ag} / \mathrm{AgCl}$ electrodes. Transepithelial resistance (TEER) was calculated according to Ohm's law. FITC-dx4 (MW=4000Da, 1mg/ml; Sigma-Aldrich, St. Louis, USA) was added to the mucosal compartment to measure paracellular passage. Serosal samples were collected every 30 min during $2 \mathrm{~h}$, of which the fluorescence level was measured using the FLUOstar Omega (BMG Labtech, Isogen Life Sciences, The Netherlands). Passage of FITC-dx4 was calculated by averaging the time point 60,90 , and 120 min of the 4 biopsies and presented in pmol. 


\section{Appendix I}

Immunohistochemical analysis of CD11c (dendritic cell populations) in the duodenum.

In order to assess if the dentritic cell population is increased in cirrhosis we determined the number of CD11c positive cells by immunohistochemistry.

\section{A}
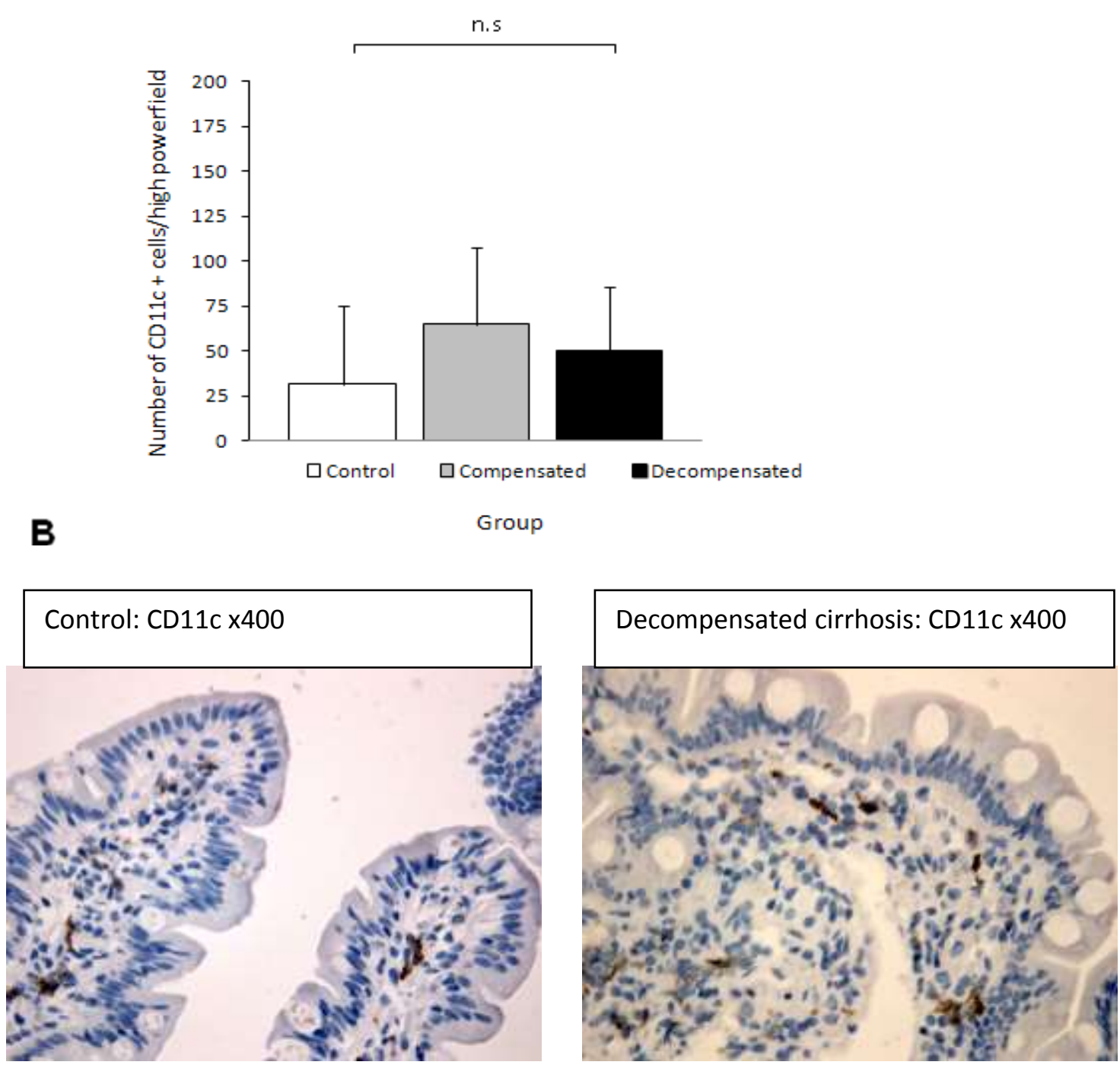

Supplementary Fig. 1 A and B. There was no increase in the numbers of CD11c positive cells observed between the groups. 


\section{Appendix $\mathbf{J}$}

Supplementary Table 6: Gene expression results in decompensated and compensated cirrhosis compared to controls.

\begin{tabular}{|c|c|c|c|c|}
\hline Gene symbol & $\begin{array}{l}\text { Decompensated } \\
\text { Fold regulation }\end{array}$ & p-value & $\begin{array}{l}\text { Compensated } \\
\text { Fold regulation }\end{array}$ & p-value \\
\hline \multicolumn{5}{|c|}{ Toll-like receptors } \\
\hline TLR1 & 1.04 & $p=0.87$ & 1.14 & $p=0.67$ \\
\hline TLR2 & 1.37 & $p=0.16$ & 1.13 & $p=0.52$ \\
\hline TLR4 & 1.30 & $p=0.20$ & 1.36 & $p=0.22$ \\
\hline TLR6 & 1.10 & $p=0.55$ & 1.28 & $p=0.20$ \\
\hline TLR9 & 1.06 & $p=0.63$ & 1.15 & $p=0.50$ \\
\hline \multicolumn{5}{|c|}{ NOD-like receptors } \\
\hline NOD1 & 0.98 & $p=0.81$ & 0.92 & $p=0.72$ \\
\hline NOD2 & 1.19 & $p=0.48$ & 1.09 & $p=0.74$ \\
\hline \multicolumn{5}{|c|}{ Signalling pathway molecules and transcription factors } \\
\hline TIRAP & 0.87 & $p=0.32$ & 1.01 & $p=0.99$ \\
\hline TRAF6 & 0.92 & $p=0.47$ & 0.84 & $p=0.51$ \\
\hline MAPK1 & 1.11 & $p=0.33$ & 1.02 & $p=0.87$ \\
\hline MAPK8 & 1.03 & $p=0.74$ & 0.97 & $p=0.83$ \\
\hline MAPK14 & 0.97 & $p=0.78$ & 0.86 & $p=0.61$ \\
\hline JUN & 0.80 & $p=0.51$ & 0.94 & $p=0.82$ \\
\hline NFKB1 & 1.17 & $p=0.13$ & 0.95 & $p=0.73$ \\
\hline CEBPB & 1.07 & $p=0.65$ & 0.90 & $p=0.73$ \\
\hline \multicolumn{5}{|c|}{ Tight junctions } \\
\hline GJA1 & 1.22 & $p=0.22$ & 1.08 & $p=0.78$ \\
\hline TJP1 & 0.95 & $p=0.72$ & 0.88 & $p=0.69$ \\
\hline CLDN1 & 1.13 & $p=0.60$ & 0.88 & $p=0.68$ \\
\hline CLDN2 & 1.28 & $p=0.47$ & 0.86 & $p=0.78$ \\
\hline OCLN & 0.87 & $p=0.27$ & 0.80 & $p=0.33$ \\
\hline \multicolumn{5}{|c|}{ Cytokines and molecules involved in inflammatory response } \\
\hline NOS2/iNOS & 2.69 & $p=0.04^{*}$ & 1.45 & $p=0.35$ \\
\hline CCL2 & 2.57 & $\mathrm{p}<0.01^{*}$ & 1.94 & $p=0.10$ \\
\hline CCL13 & 4.35 & $\mathrm{p}<0.01^{*}$ & 2.03 & $p=0.25$ \\
\hline IL8 & 2.84 & $p=0.02^{*}$ & 1.51 & $p=0.17$ \\
\hline IL10 & 1.20 & $p=0.56$ & 1.32 & $p=0.40$ \\
\hline IL22 & 0.94 & $p=0.80$ & 0.85 & $p=0.57$ \\
\hline TGFB1 & 1.10 & $p=0.61$ & 1.20 & $p=0.43$ \\
\hline
\end{tabular}

${ }^{*}$ significant if fold regulation is $>2$ and is $p<0.05$ 


\section{Appendix K}

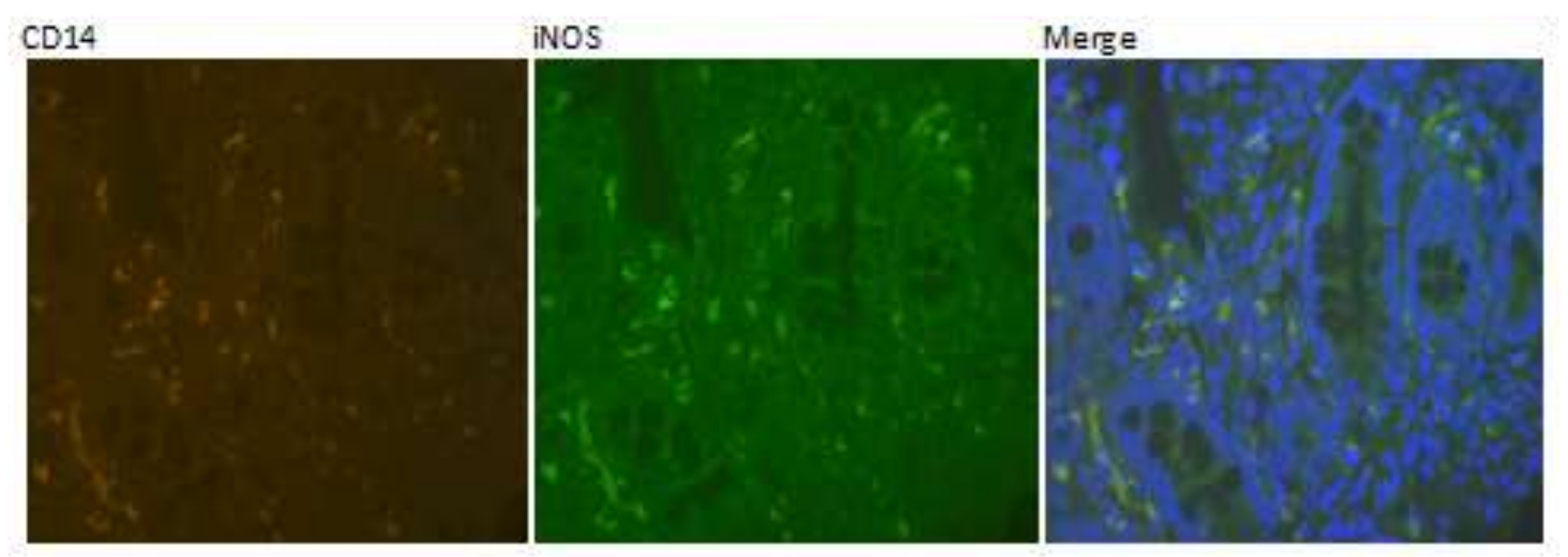

Supplementary Fig. 2: Co-localization studies confirmed that all CD14 positive cells were iNOS positive. To confirm the presence of classically activated macrophages in the duodenum of patients with cirrhosis, co-localization studies were performed. We demonstrated that all CD14+ macrophages were iNOS positive confirming the presence of classically activated intestinal macrophages in decompensated cirrhosis 


\section{Appendix L}

Immunohistochemical analysis of IL-6

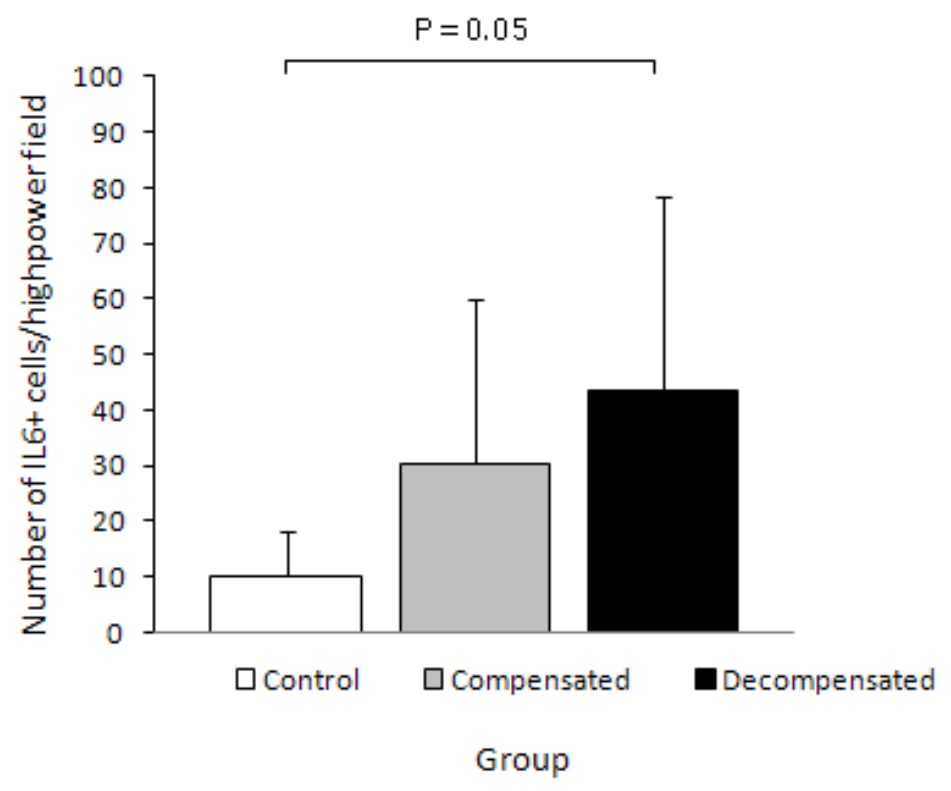

Supplementary Fig. 3. There was a significant increase in the number of cells that stained positive for IL-6 in decompensated patients compared to controls $(43.30 \pm 35.3$ vs.10.13 $\pm 8.30 ; p=0.05$ ) 


\section{Appendix M}

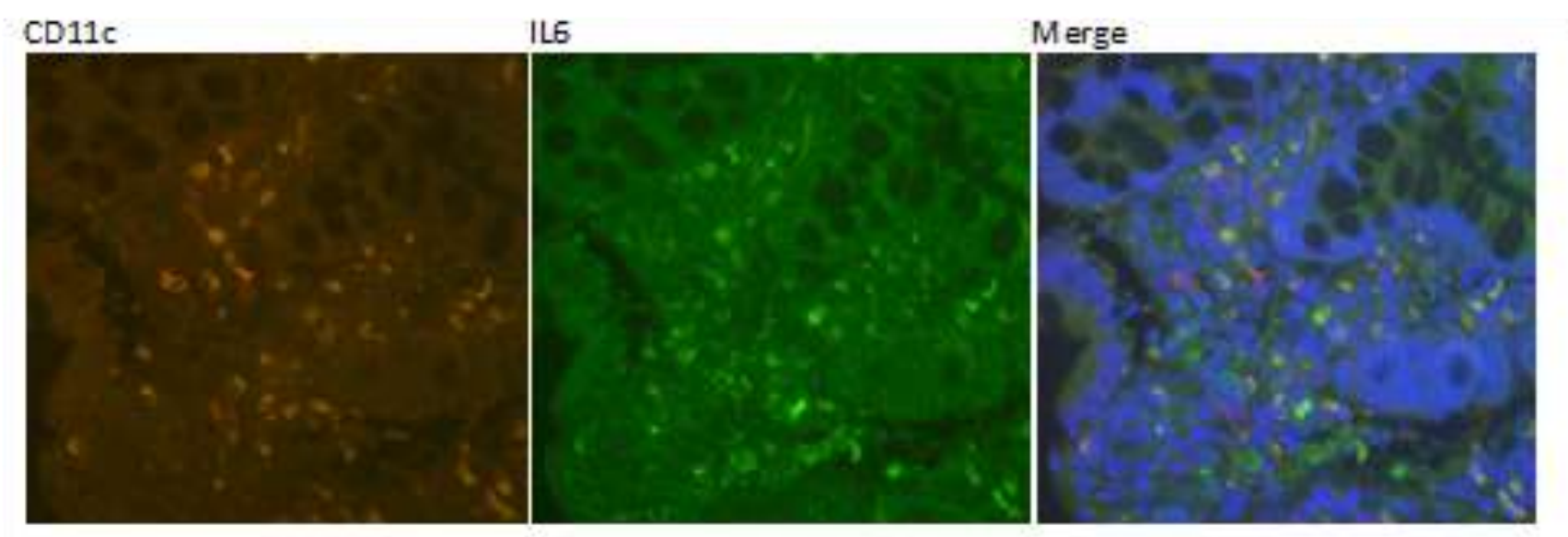

Supplementary Fig. 4: Co-localization studies showed that CD11c positive dendritic cells are not the main cell source of IL6. IL-6 was predominantly present in CD11c negative cells indicating that dendritic cells are not the main producers of this pro-inflammatory cytokine 


\section{Appendix N}

Summarized results for Western blot analysis of tight junction proteins

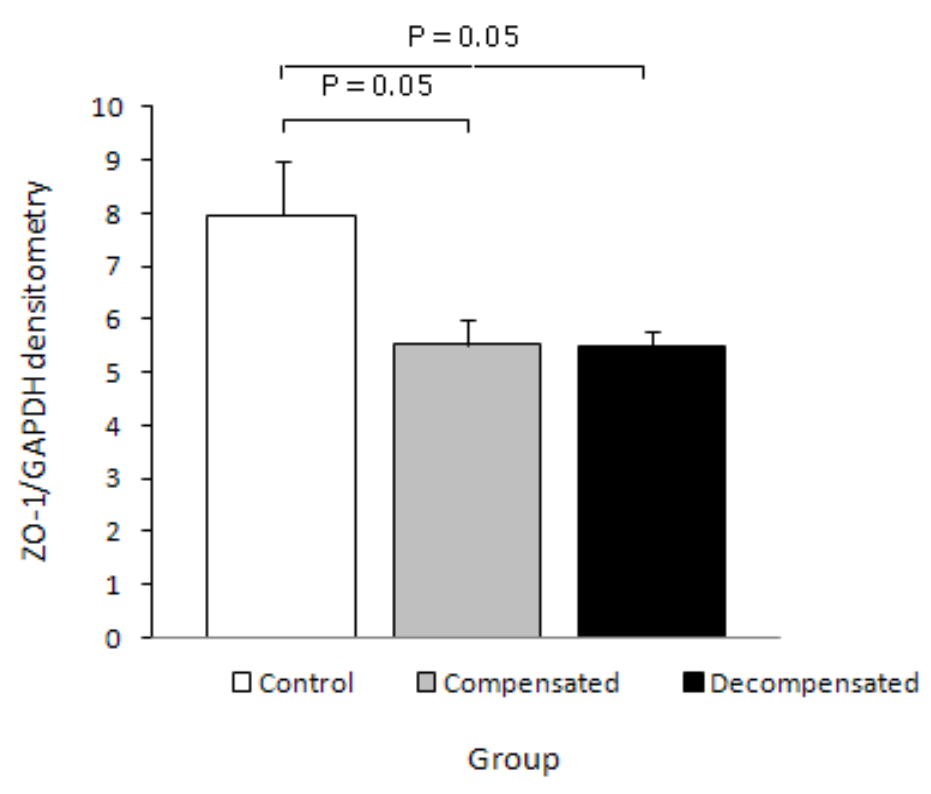

Supplementary Fig. 5. No differences were detected in the protein levels of ZO-1 by western blot analysis between the groups.

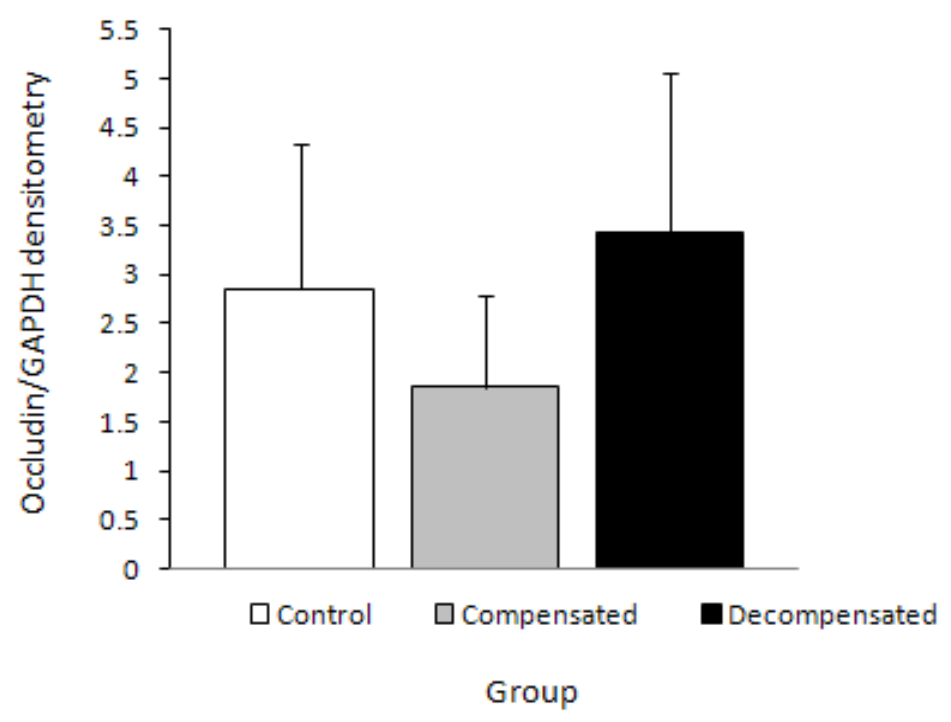

Supplementary Fig. 6. No differences were detected in the protein levels of Occludin by western blot analysis between the groups. 


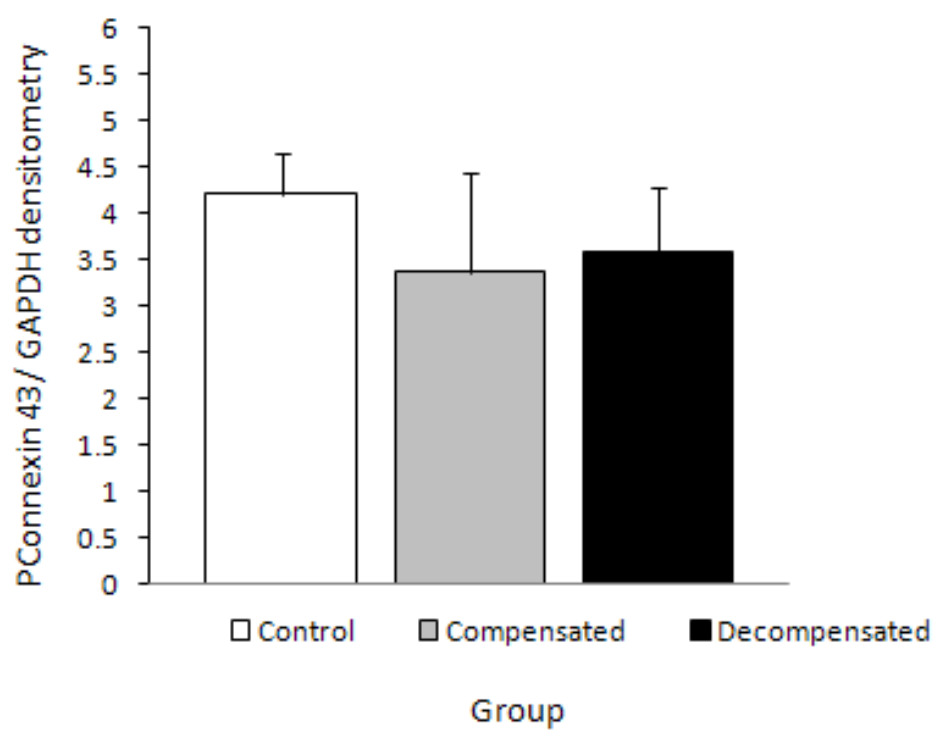

Supplementary Fig. 7. No differences were detected in the protein levels of Phosphorilated connexion- 43 by western blot analysis between the groups.

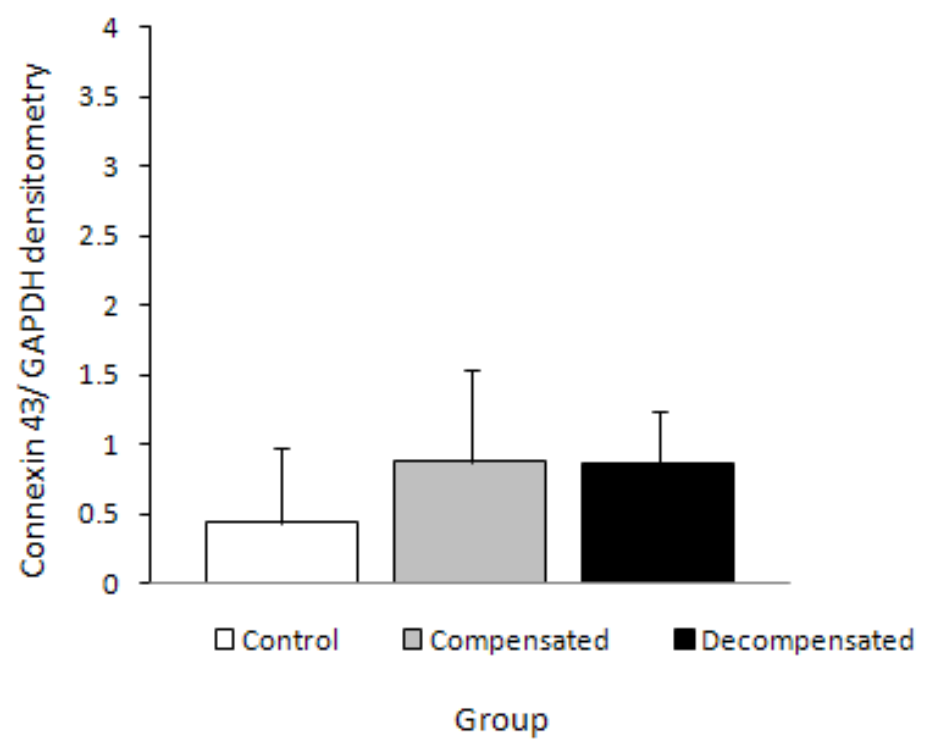

Supplementary Fig. 8. No differences were detected in the protein levels of Connexion-43 by western blot analysis between the groups. 


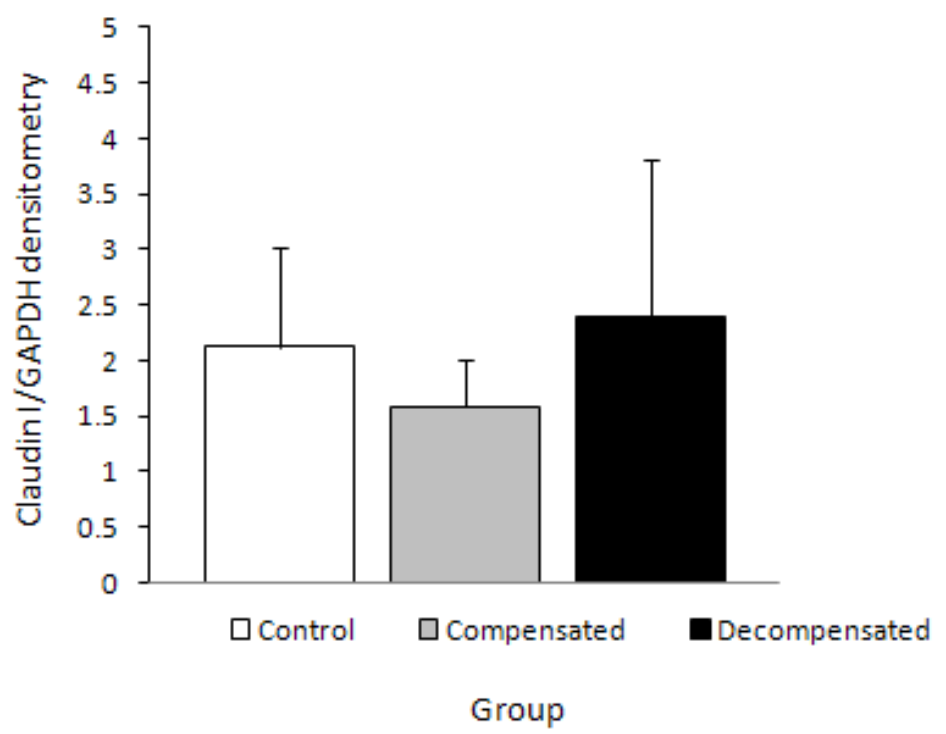

Supplementary Fig. 9: No differences were detected in Claudin-1 protein levels by western blot analysis between the groups. 